\title{
Recent developments in synthetic chemistry and biological activities of pyrazole derivatives
}

\author{
MUHAMMAD FAISAL*(i), AAMER SAEED*, SARWAT HUSSAIN, PARSA DAR and \\ FAYAZ ALI LARIK \\ Department of Chemistry, Quaid-i-Azam University, Islamabad 45320, Pakistan \\ E-mail:mfaisal4646@gmail.com; aamersaeed@yahoo.com
}

MS received 10 January 2019; revised 13 March 2019; accepted 18 May 2019

\begin{abstract}
Pyrazole, a five-membered heterocycle containing two nitrogen atoms, is extensively found as a core framework in a huge library of heterocyclic compounds that envelops promising agro-chemical, fluorescent and biological potencies. Attributed to its several potential applications, there is a rise in the significance of designing novel pyrazoles, disclosing innovative routes for synthesizing pyrazoles, examining different potencies of pyrazoles, and seeking for potential applications of pyrazoles. This review consists of two parts. The first part provides an overview on the recent developments in synthetic approaches to pyrazoles, which is related to the new or advanced catalysts and other 'environment-friendly' procedures, including heterogeneous catalytic systems, ligand-free systems, ultrasound and microwave-assisted reactions. The second part focuses on the recently reported novel biological affinities of pyrazoles. This systematic review covers the published studies from 1990 to date. It is expected that this review will be helpful in future research and for new thoughts in the quest for rational designs for developing more promising pyrazoles.
\end{abstract}

Keywords. Pyrazole; pharmaceutical activities; biological activities; synthesis; green chemistry; polycondensed compounds.

\section{Introduction}

Heterocyclic compounds are a highly valuable and unique class of compounds. These compounds demonstrate a broad spectrum of physical, chemical and biological characteristics. ${ }^{1,2}$ In nature, heterocyclic compounds are widely distributed and display an important part in metabolism owing to their structural nucleus occurring in various natural products, including hormones, antibiotics, alkaloids, vitamins and many others. $^{3-5}$

Amongst heterocyclic compounds, nitrogen-containing heterocycles are extensively found as a core framework in a huge library of heterocycles and show several employments in natural science and other areas of science. ${ }^{6}$ Additionally, nitrogen-containing heterocycles have striking structural features and they are widely observed in natural products, for instance, vitamins, hormones and alkaloids. ${ }^{7,8}$ Pyrazole $\mathbf{1}$ is known to be one of the most potential families of nitrogen-containing compounds. Pyrazole derivatives exhibit a broad spectrum of biological profiles, for instance, anti-tubercular, ${ }^{9}$ anti-AIDS, ${ }^{10}$ anti-malarial, ${ }^{8}$

\footnotetext{
*For correspondence
}

anti-microbial, ${ }^{11}$ antitumor, ${ }^{12,13}$ anticancer ${ }^{14}$ and antifungal. ${ }^{6}$ In addition, pyrazoles have also been found as promising anti-hyperglycemic, ${ }^{15}$ anti-depressant, ${ }^{16}$ anti-convulsant, ${ }^{17}$ anti-pyretic, ${ }^{18}$ anti-anxiety ${ }^{19,20}$ and insecticidal agents. ${ }^{21}$ Bipyrazole shows diuretic, cytotoxic and cardiovascular efficacy. ${ }^{19}$ It has achieved great attention since the privileged framework is frequently observed as a bioactive component in commercially available medicines, for example, Floxan $\mathbf{2}$ (anti-inflammatory medicine), pyrazomycin $\mathbf{3}$ (anticancer), difenamizole 4 (anti-inflammatory drug), and deramaxx 5 (NSAID) (Figure 1). ${ }^{22,23}$ It is also utilized in paint and photographic industries and in the development of heat resistant resins. ${ }^{24}$ The corresponding 3-oxygenated derivative, pyrazolone $\mathbf{6}$, which has an additional keto-group, is the basic component in drugs such as metamizole sodium and phenylbutazone (both are non-steroidal anti-inflammatory medicines, generally used as powerful painkillers and fever reducers) (Figure 1). ${ }^{19}$ Also, the benzo-fused derivative of pyrazole (i.e., tetrahydroindazole 7) is well-known to be biologically active, and used against cancer ${ }^{25}$ and inflammation. ${ }^{26}$ Indole $\mathbf{8}$, which is an isostere of indazole, is perhaps the most commonly found heterocyclic system 


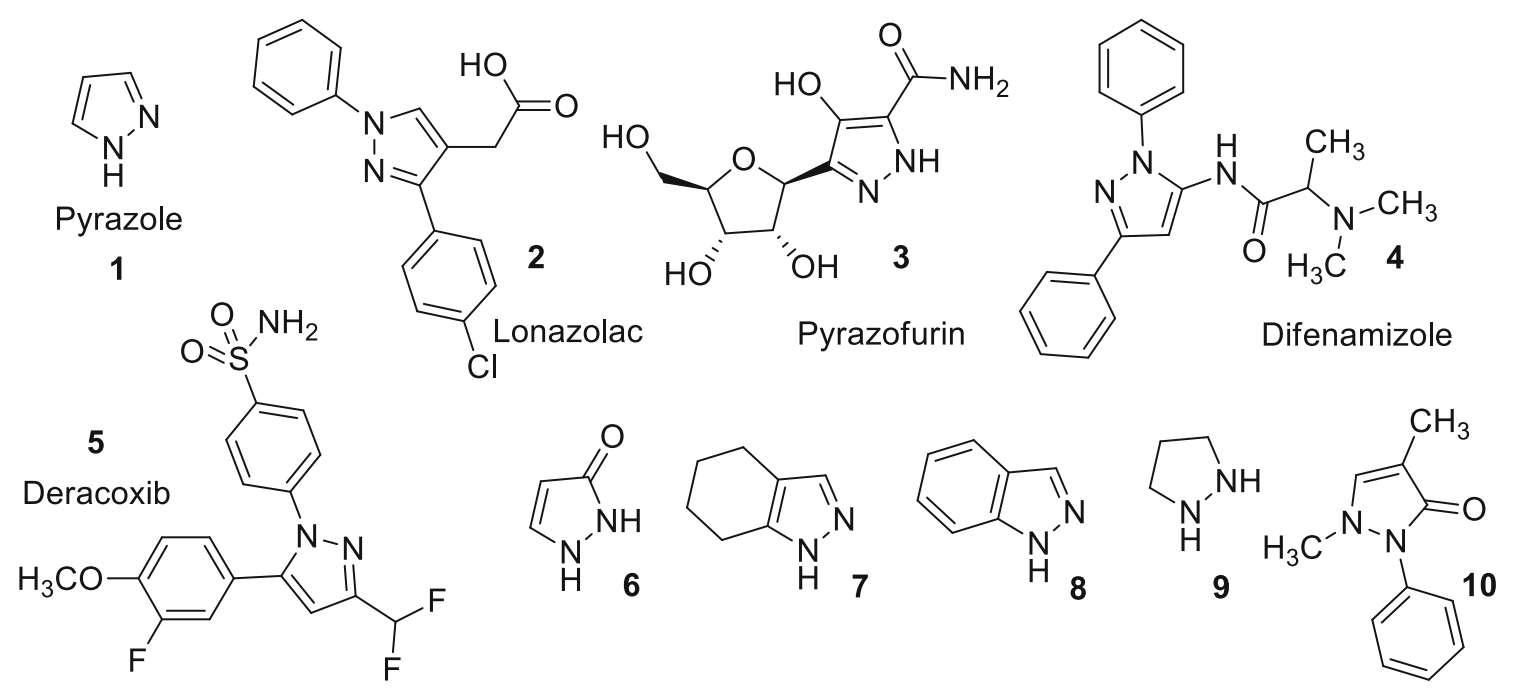

Figure 1. Structures of important pyrazole derivatives.

in nature. For instance, the essential neurotransmitters in the central nervous system, serotonin and the crucial amino acid, tryptophan are two out of several important indole derivatives (Figure 1). ${ }^{27}$

Chemically, in the basic structure, pyrazole $\mathbf{1}$ has two nitrogen atoms at adjacent positions in the fivemembered ring. The molecular formula of pyrazole $\mathbf{1}$ is $\mathrm{C}_{3} \mathrm{H}_{4} \mathrm{~N}_{2}$ which has $6 \pi$ electrons delocalized over the ring forming an aromatic system. Pyrazole is closely linked to several of its reduced or oxidized forms such as pyrazoline (11, 12 and 13), pyrazolidine 9, and pyrazolone 10. Unlike pyrazole, pyrazoline, and pyrazolidine are not aromatic compounds due to the lack of conjugation and delocalization of $\pi$ electrons (Figures 1 and 2). ${ }^{28}$

In synthetic chemistry, the development of novel and productive approaches for the synthesis of pyrazole derivatives along with their bioactivities examination is known to be an important and continuing challenge. This review provides an extensive summary of progress over the last decade for the formation of pyrazoles as well as their biological profile. We hope that this review will be useful for scientists working in the area of synthetic and medicinal chemistry.

\section{Aromaticity, chemical reactivity and physical properties of pyrazole}

\subsection{Aromatic character of pyrazole}

Pyrazole $\mathbf{1}$ is a five-membered aromatic heterocyclic compound. Pyrazole is a pi-excessive heterocyclic system, which contains two nitrogen atoms; one is pyrrole type at position-1; while, other is pyridine type at

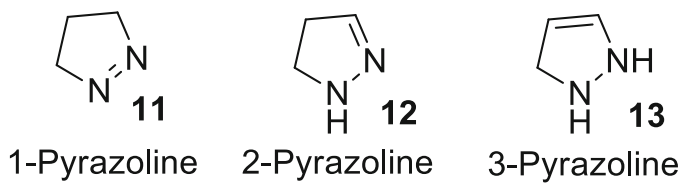

Figure 2. Structures of pyrazolines.

position-2. Among the two nitrogens, one is basic and the other is neutral in nature. The aromatic nature in pyrazole systems appears from the unshared pair of electrons on the $-\mathrm{NH}$ nitrogen and the four pi-electrons. Pyrazole exists in three partially reduced forms, i.e., 1-pyrazoline 11, 2-pyrazoline 12 and 3-pyrazoline 13 (Figure 2). ${ }^{29}$

These are also aromatic systems attributed to their conjugated planar ring frameworks with six highly delocalized $p i$-electrons. It is found from various experimental investigations that the bond length between atoms at position 3 and 4 has a high value. ${ }^{30}$ 2-Pyrazolines 12 are observed to be the most commonly examined pyrazoline-type heterocyclic systems (Figure 2). ${ }^{31}$

\subsection{Chemical reactivity of pyrazole}

The chemical reactivity of pyrazole 1 can be described by the effect of individual atoms. The nitrogen atom at position- 2 with lone pair of electrons is moderately basic in nature and thus reacts with electrophilic centers of reagents. The nitrogen atom at position- 1 is not reactive but gives up its $\mathrm{H}^{+}$in the existence of the base. The combined effect of two nitrogen atoms reduces the charge density at carbon-3 and carbon-5, making them vacant for attack by electrophilic reagents. Removal of $\mathrm{H}^{+}$at carbon-3 can take place in the existence of a strong base, ending in the opening of the ring. Addition of $\mathrm{H}^{+}$ ions to pyrazoles results in the formation of pyrazolium ions which are less likely to experience electrophilic 


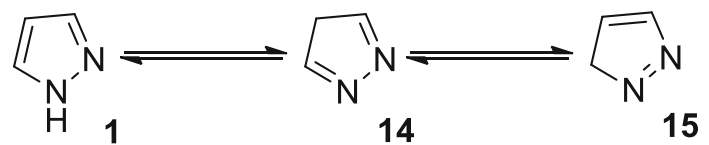

Figure 3. Three tautomeric structures of pyrazole.

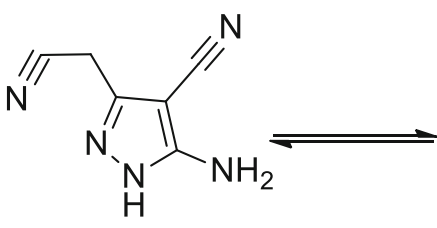

16<smiles>N#CCc1[nH]nc(N)c1C#N</smiles>

17
Figure 4. Tautomeric forms of 16 .

attack at carbon-4, but an electrophilic attack at carbon-3 is facilitated. The anions of pyrazole are much less reactive toward nucleophilic attack, but the reactivity toward electrophiles is enhanced..$^{32}$ Owing to their planar conjugated ring skeletons with 6 highly delocalized pi-electrons, pyrazole molecules are aromatic heterocycles. Hence, various significant properties of pyrazoles have been investigated by matching with the properties of benzene analogues. ${ }^{33}$ Like other nitrogen atom(s) involving heterocyclic compounds, different tautomeric forms (14 and 15) can also be written for pyrazole heterocycles. Unsubstituted pyrazole 1 can be illustrated in three tautomeric structures (Figure 3). ${ }^{34}$

5-Amino-3-(cyanomethyl)-1H-pyrazol-4-yl cyanide 16 is a pi-excessive aromatic monocyclic heterocyclic compound having two $\mathrm{N}$-atoms in a 5-membered 1,2diazole ring, there are three sites for electrophilic attack in pyrazole moiety $\mathbf{1 6}$ which is in tautomeric equilibrium with 17 , the active methylene group and the amino group, whereas two such sites are also available for nucleophilic attack, the carbon atom of the conjugated nitrile group and the carbon atom of the non-conjugated nitrile group (Figure 4). ${ }^{35}$

\subsection{Chemical and physical properties of pyrazole}

Unsubstituted pyrazole $\mathbf{1}$ is a colorless solid with a melting point in the range of $69-70{ }^{\circ} \mathrm{C}$. The boiling point of unsubstituted pyrazole is in the range of $186-188^{\circ} \mathrm{C}$ that is attributed to intermolecular H-bonding. The ionization potential of this molecule is $9.15 \mathrm{eV}$. It follows from a comparison with an azole (having ionization potential of $8.231 \mathrm{eV}$ ) that pyridine-like nitrogen-atom reduces the energy of the HOMO (highest occupied molecular orbital), indeed even more so than in the case of 1,3diaza-2,4-cyclopentadiene (with ionization potential of $8.782 \mathrm{eV}$ ) (Table 1). The dipole moment $(\mu)$ of pyrazole 1 in benzene is estimated to be $1.921 \mathrm{D}$ (Debye). The value of $\mu$ relies on the concentration of pyrazole $\mathbf{1}$ because cyclic dimers of pyrazole $\mathbf{1}$ develop at higher concentrations in compound $\mathbf{1}$. The $\mu$ is directed from
Table 1. Physical properties of pyrazole.

\begin{tabular}{ll}
\hline Property name & Property value \\
\hline Molecular formula & $\mathrm{C}_{3} \mathrm{H}_{4} \mathrm{~N}_{2}$ \\
Formula weight & 68.07726 \\
Composition & $\mathrm{C}(52.93 \%), \mathrm{H}(5.92 \%), \mathrm{N}(41.15 \%)$ \\
Molar refractivity & $18.17 \pm 0.3 \mathrm{~cm}^{3}$ \\
Molar volume & $60.9 \pm 3.0 \mathrm{~cm}^{3}$ \\
Parachor & $161 \pm 4.0 \mathrm{~cm}^{3}$ \\
Index of refraction & $1.528 \pm 0.02$ \\
Surface tension & $48.6 \pm 3.0$ dyne/cm \\
Dielectric constant & Not available \\
Polarizability & $7.44 \pm 0.5 \times 10^{-24} \mathrm{~cm}^{3}$ \\
Monoisotopic mass & $68.037448 \mathrm{Da}$ \\
Nominal mass & $68 \mathrm{Da}$ \\
Average mass & $68.078461 \mathrm{Da}$ \\
\hline
\end{tabular}

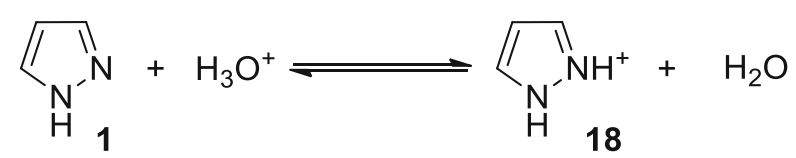

Figure 5. Acidic behavior of pyrazole.

the center of the pyrazole to the bond between atoms 2 and 3. In most pyrazole reactions, a similarity with 1,3diaza-2,4-cyclopentadienes is evident, and contrasts are also possible. ${ }^{36,37}$

\subsection{Acid-base reactions}

Unsubstituted pyrazole $\mathbf{1}$ displays acidity due to $-\mathrm{NH}$ group present at position- 1 . The $\mathrm{pK}_{\mathrm{a}}$ value of pyrazole $\mathbf{1}$ is experimentally calculated to be 14.211 , which is equal to the $\mathrm{pK}_{\mathrm{a}}$ value of 1,3-diaza-2,4-cyclopentadiene (Figure 5). Pyrazolines $(\mathbf{1 1}, \mathbf{1 2}$ and $\mathbf{1 3})$ are basic in nature. It is reported that in the excited state of Pyrazoline, an intermolecular conjugated charge transfer process exists. In the conjugated part (-C3-N2-N1-) of the ring of 1 , the $\mathrm{N}$-atom at the position-3 has, respectively electron withdrawing and donating capabilities. The carbon atoms at position- 4 and position-5 are not conjugated intermolecularly with the remaining part of the ring of 1. ${ }^{37}$

\section{Nomenclature of pyrazoles and related systems}

Pyrazoles and related ring systems can be designated as $1 \mathrm{H}, 2 \mathrm{H}, 3 \mathrm{H}$ and $4 \mathrm{H}$-pyrazoles. The $2 \mathrm{H}$ and $3 \mathrm{H}$-pyrazoles (12 and 11) are called pyrazolines (2-pyrazoline 12 and 1-pyrazoline 11) and dihydropyrazoles. The designations $1 \mathrm{H}, 2 \mathrm{H}, 3 \mathrm{H}$ and $4 \mathrm{H}$ prior to the term 'pyrazole' show the position of the hydrogen atom, which resembles the lowest numbering system for the nitrogen 


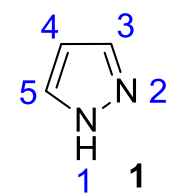

1H-pyrazole

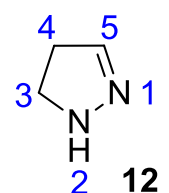

3,4-dihydro-2H-pyrazole

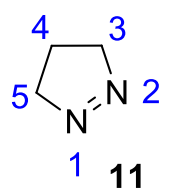

4,5-dihydro-3H-pyrazole "cyclic azo" or "pyrazoline"

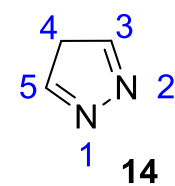

4H-pyrazole "cyclic azine"

Figure 6. The naming system for pyrazoles and related systems.

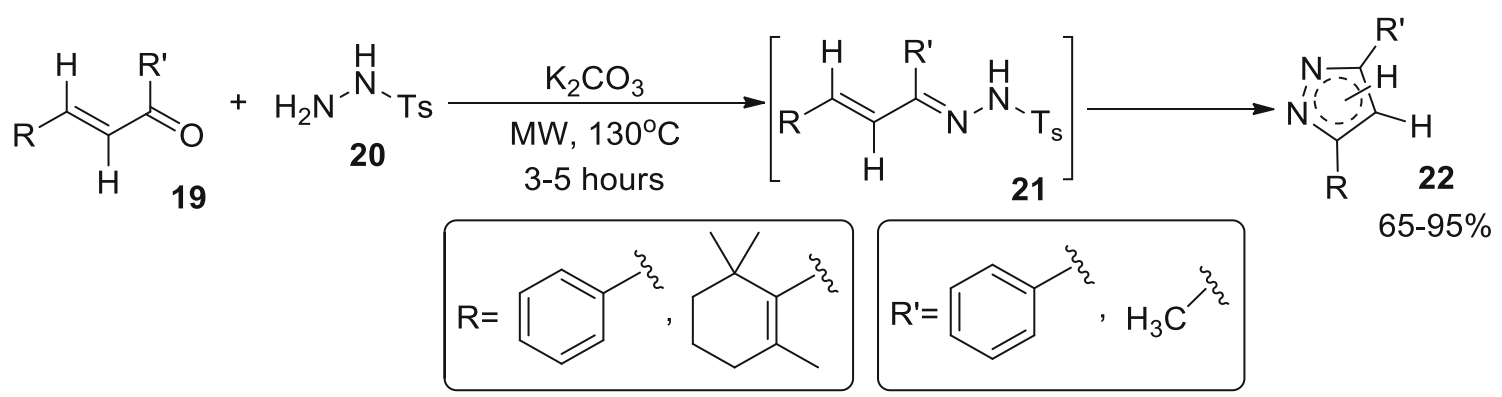

Scheme 1. Synthesis of pyrazoles form carbonyl precursors.

or the location for saturation (Figure 6). The word 'dihydro' indicates the location of a formally reduced double bond. For dihydro $2 \mathrm{H}$ or $3 \mathrm{H}$ pyrazole, the entity must contain one double bond. In order to be named as 4H-pyrazole 14, which is $a k a$. isopyrazole or cyclic azine, the entity must contain one tetrahedral carbon and two double bonds. ${ }^{38}$

\section{Methodologies for the synthesis of pyrazoles}

The pyrazole entity is a significant pharmacophore displaying a multitude of pharmacological and biological activities. Naturally, these broad biological activities render this class of compounds synthetically interesting. Consequently, new approaches for the development of this heterocyclic skeleton have attracted significant consideration during recent years. The development of methods for efficient construction of several pyrazole derivatives is the focus of this book chapter, which also includes the development of a new eco-friendly synthetic pathway to the construction of pyrazole derivatives. Also, benzo-fused and dihydropyrazolone analogues of pyrazole (i.e. indazoles and tetrahydroindazoles) are of interest in this context.

\subsection{Recent green methodologies to construct the skeleton of pyrazole analogues}

\section{1a Microwave-mediated solvent-free approach:}

An innovative solvent-less microwave-based methodology to the construction of pyrazoles 22 from tosyl hydrazones 21 (generated in situ) of $\alpha, \beta$-unsaturated carbonyls 19 having a beta-hydrogen in the presence of $\mathrm{K}_{2} \mathrm{CO}_{3}$ and $p$-toluenesulfonyl hydrazide 20 is recently disclosed by Anna Corradi et al. (Scheme 1). In this approach, activation was brought about with microwave irradiation (MWI). With the proposed microwave based solvent-less procedure, good results in terms of yields and reaction speed were observed, which indicate that this process is the eco-friendly, fast and simple synthetic route to attain pyrazoles 22 from $\alpha, \beta$-unsaturated ketones 19 having beta-hydrogen. ${ }^{39}$

$4.1 \mathrm{~b}$ One-pot deep eutectic solvent-based synthesis of polysubstituted pyrazoles: Polysubstituted pyrazoles $\mathbf{2 5}$ were efficiently synthesized by Beyzaei et al., through two-step one-pot procedure. In this technique, the reaction of 2,4-dinitrophenylhydrazine $\mathbf{2 5}$, malononitrile 23, and different aldehydes $\mathbf{2 4}$ in deep eutectic solvent (DES) were carried out. ${ }^{40}$ In order to obtain optimized results and investigate the effectiveness of DES towards the synthesis of pyrazoles, some deep eutectic solvents having different molar ratios of potassium carbonate to glycerol were prepared and employed as reaction bath and catalyst in this synthetic approach. The finest results in terms of product yields and reaction times were achieved in molar ratios 1:4:14 of $\mathrm{K}_{2} \mathrm{CO}_{3} /$ glycerol $/ \mathrm{H}_{2} \mathrm{O}$ (Scheme 2 ). In the existence of $\mathrm{DES}$, the reaction times and productivity of reactions were improved considerably.

4.1c Catalyst-free and eco-friendly formation of phthalide-fused pyrazole derivatives: A promising catalyst-free and eco-friendly procedure for the 


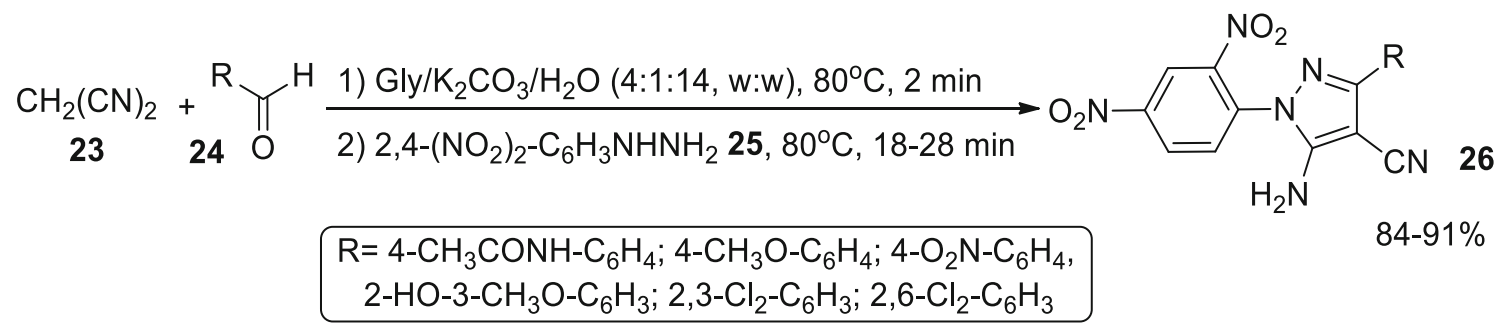

Scheme 2. Synthesis of polysubstituted pyrazoles using deep eutectic solvent.<smiles>[R]C#CC(=O)O[Z17](N)N</smiles><smiles>[R]c1n[nH]c(O)c1C1OC(=O)c2ccccc21</smiles>

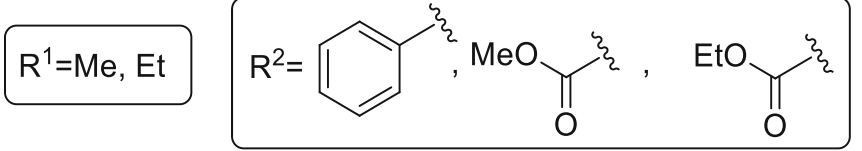

Scheme 3. Development of phthalide-fused pyrazole derivatives.

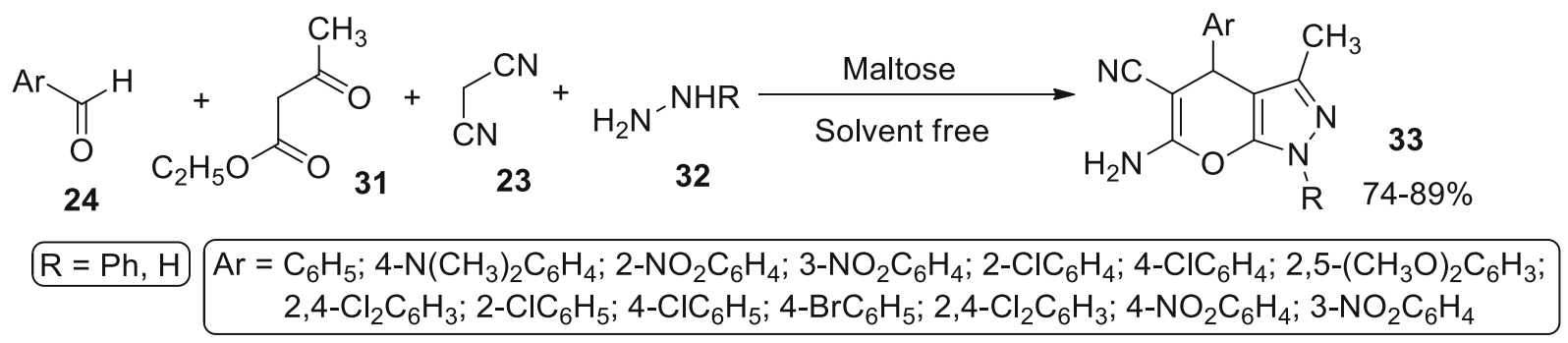

Scheme 4. Formation of 1,4-dihydropyrano[2,3-c]pyrazoles using maltobiose.

formation of phthalide-fused pyrazole derivatives $\mathbf{3 0}$ through condensation of acetylenic ester $\mathbf{2 7}$, hydrazine monohydrate $\mathbf{2 8}$ and phthalaldehydic acid $\mathbf{2 9}$ in water at $100{ }^{\circ} \mathrm{C}$ for one day is disclosed by A. Bazgir and co-workers. ${ }^{41}$ The course of work-up of these eco-friendly reactions required only filtration and subsequent washing with excess methanol (Scheme 3). Further, this method shows remarkable characteristics, for instance, application of $\mathrm{H}_{2} \mathrm{O}$ as a solvent, uncomplicated workup of products, and reduced waste formation without employing any catalyst or additive.

4.1d Eco-friendly formation of 1,4-dihydropyrano[2, 3-c]pyrazoles through biodegradable catalyst maltobiose: A novel and highly effective technique for fourcomponent one-pot preparation of highly derivatized 1,4-dihydropyrano[2,3-c]pyrazoles $\mathbf{3 3}$ using phenylhydrazine or hydrazine monohydrate $\mathbf{3 2}$, acetoacetic ester 31, malononitrile 23 and aldehydes 24 under thermal and solvent-less conditions with maltobiose as a catalyst has been unveiled by Kangani et al. ${ }^{42}$ The reaction efficiently proceeded to produce the respective products 33 (Scheme 4). Use of inexpensive and non-toxic materials, short reaction times, simple and clean work-up, non-hazardous catalyst, minimum pollution of the environment, operational simplicity and excellent yields of the pyrazoles are the benefits of this technique.

4.1e Eco-friendly TBAB-based formation of pyrazoles under solvent-less conditions: Soltanzadeh et al., disclosed a green, environment-friendly, novel and inexpensive technique for the production of a library of pyrazoles $37 .{ }^{43}$ The reaction took place in the existence of $N$ '-benzoylbenzohydrazide 34,35 , isocyanide 36 and tetrabutylammonium bromide (TBAB; a commercially available organic ionic salt) at r.t. under solvent-less conditions for 0.5-12 h (Scheme 5). Operational simplicity, excellent yields of the pyrazoles (75-86\%) and short times of reaction are the merits of this technique. 


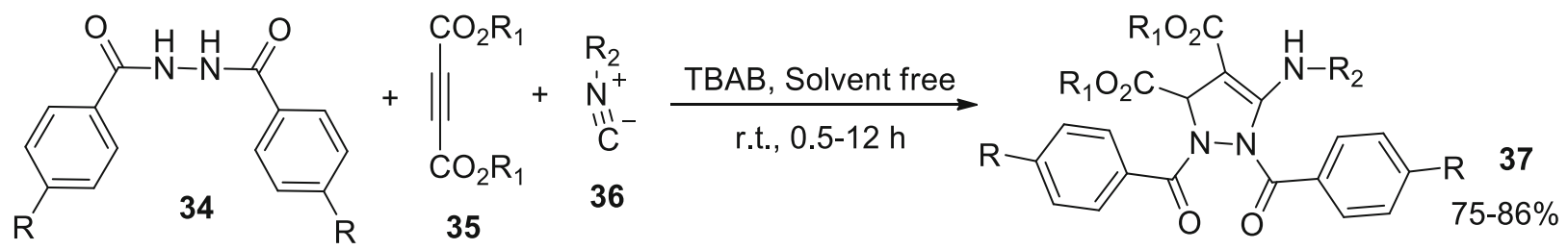

$$
\mathrm{R}=\mathrm{H}, \mathrm{NO}_{2} \quad \mathrm{R}_{1}=\mathrm{CH}_{3}, \mathrm{CH}_{3} \mathrm{CH}_{2} \quad \mathrm{R}_{2}=\text { Cyclohexyl, }\left(\mathrm{CH}_{3}\right)_{3} \mathrm{C}
$$

Scheme 5. Development of pyrazole cores using TBAB.

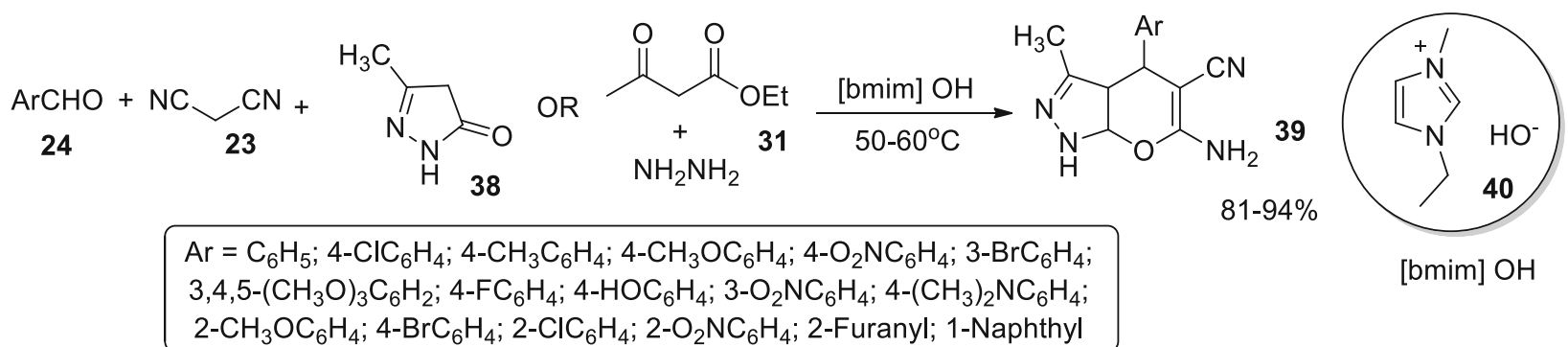

Scheme 6. Construction of $4 H$-pyrano[2,3-c]pyrazoles using [bmim]OH.
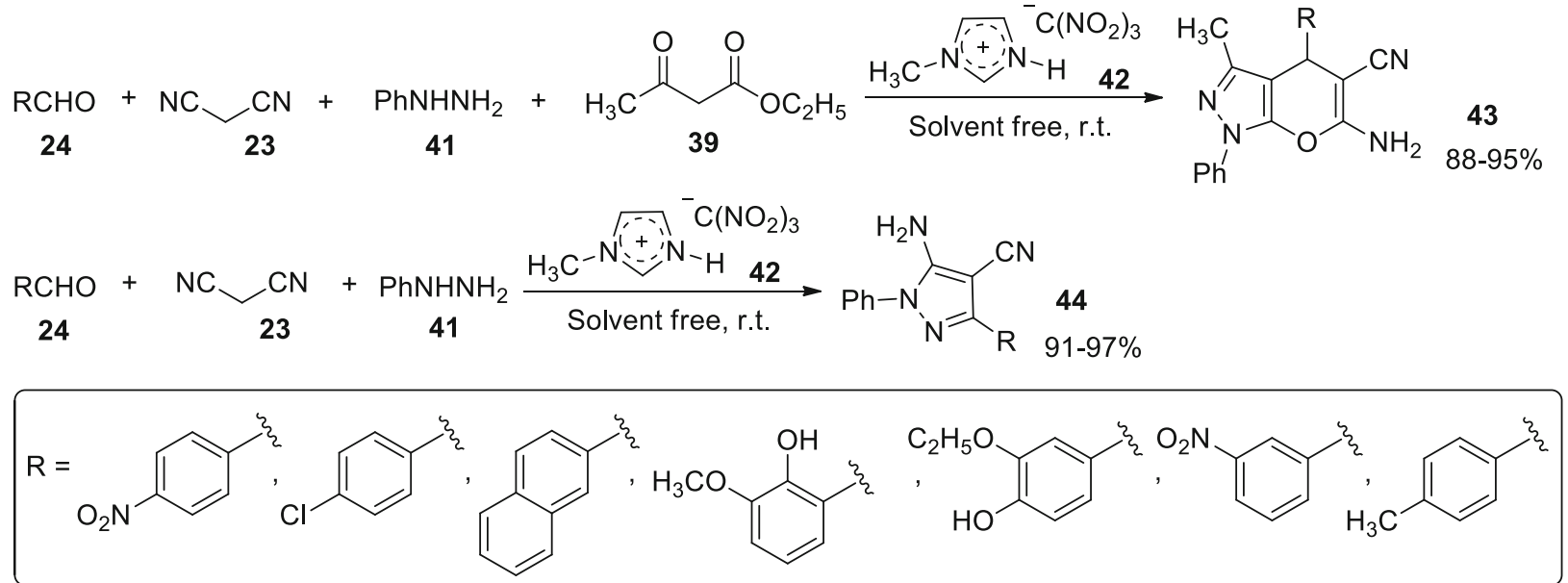

Scheme 7. Construction of pyrazole frameworks using NIL as catalyst.

4.1f Eco-friendly development of pyrazole frameworks using IL [bmim]OH: A unique and appropriate technique for the preparation of $4 H$-pyrano[2,3-c]pyrazole derivatives $\mathbf{3 9}$ by three-component condensation reaction of malononitrile $\mathbf{2 3}$, aryl-aldehydes $\mathbf{2 4}$ and pyrazolone $\mathbf{3 8}$ or four-component condensation reaction of malononitrile $\mathbf{2 3}$, hydrazine monohydrate, aromatic aldehydes $\mathbf{2 4}$ and acetoacetic ester $\mathbf{3 1}$ using [bmim] $\mathrm{OH}$ 40 as ionic liquid (IL) at $50-60{ }^{\circ} \mathrm{C}$ has been disclosed by Khurana et al. ${ }^{44}$ The procedure was expressed to be environmentally benign and efficient in terms of excellent yields, ease of recovery, low reaction times and recyclability of reaction medium (Scheme 6). 4.1g Synthesis of pyrazole derivatives by 1-methylimidazolium trinitromethanide: a nano-IL: In the report of Zolfigol et al., an effective and green NIL catalystviz., 1methylimidazolium trinitromethanide $\{[\mathrm{HMIM}] \mathrm{C}$ $\left.\left(\mathrm{NO}_{2}\right)_{3}\right\} \mathbf{4 2}$ was employed in the formation of 5-aminopyrazole-4-carbonitriles $\mathbf{4 4}$ by the three-component condensation reaction of malononitrile $\mathbf{2 3}$, aryl aldehydes 24, and phenyl hydrazine 41 under solventless conditions at r.t. (Scheme 7). 1,4-Dihydropyrano$[2,3-c]$-pyrazoles $\mathbf{4 3}$ were also prepared via four-component condensation reaction of malononitrile $\mathbf{2 3}$, aryl aldehydes $\mathbf{2 4}$, ethyl acetoacetate $\mathbf{3 9}$ and phenyl hydrazine $\mathbf{4 1}$ under similar reaction conditions. ${ }^{45}$ 
<smiles>[X]c1ccc(NN)cc1</smiles><smiles>[Y][X](=O)=O</smiles>

Scheme 8. Chemoselective preparation of pyrazoles using Lewis acid-based IL.
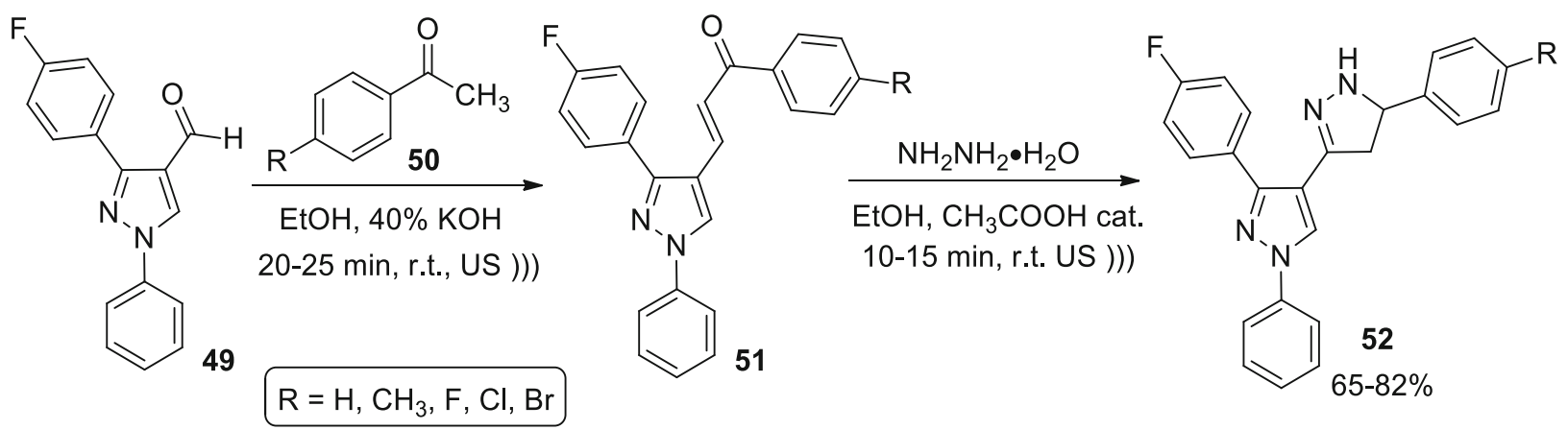

Scheme 9. Formation of fluorinated derivatives of pyrazoline using ultrasonic irradiation.<smiles>[R]c1ccc(-c2nn(-c3ccc(C=O)cc3)c(N)c2C#N)cc1</smiles>

53 24 54 $88-92 \%$

$\mathrm{R}=4-\mathrm{Br} ; 4-\mathrm{CF}_{3} ; 2-\mathrm{Cl} ; \mathrm{H} ; 4-\mathrm{OH} ; 4-\mathrm{MeO} ; 2-\mathrm{Br} ; 3,4-(\mathrm{OH})_{2} ; 2,5-(\mathrm{OH})_{2}$; anthracene; 2,4- $(\mathrm{OH})_{2} ; 2,3-(\mathrm{OH})_{2}$

Scheme 10. Formation of pyrazole analogues using copper(II) oxide in zirconium dioxide.

The disclosed reactions by Zolfigol et al., were in fair agreement with the disciplines of green synthesis and their key benefits are ease of separation, cleaner reaction profile, reasonably high productivity, short times of reaction and recyclability of NIL.

\section{1h Copper(II) IL for chemoselective green prepara-} tion of highly functionalized pyrazoles: A chemoselective, eco-friendly, novel and effective technique for the production of highly substituted pyrazoles 48 by the one-pot reaction of aldehydes 45 , aryl-hydrazine 46 and dimethyl 2-butynedioate 47 in the presence of Lewis acidic IL $\left[n-\mathrm{Bu}_{4} \mathrm{P}\right]\left[\mathrm{CuBr}_{3}\right]$ as a reusable catalyst has been described by Safaei et al. ${ }^{46}$ This catalytic system is chemoselective and simple with excellent yields (Scheme 8). Short times of reaction, straightforward operation, eco-friendliness and elimination of the application of toxic reagents, as well as organic solvents, are remarkable benefits of the present technique. 4.1i Green formation of fluorinated pyrazolines by means of ultrasonic irradiation: A library of fluorinated pyrazoles $\mathbf{5 2}$ were constructed by Shelke et al. ${ }^{47}$ in reasonable yields (65-82\%) from the respective fluorinated-chalcones $\mathbf{5 1}$ by using ultrasonic irradiation and the reaction took place in the presence of hydrazine monohydrate, ethanol and $\mathrm{AcOH}$ (Scheme 9). The fluorinated-chalcones $\mathbf{5 1}$ were obtained through the reaction of aldehydes $\mathbf{4 9}$ and aromatic ketones $\mathbf{5 0}$ in the existence of $40 \% \mathrm{KOH}$ in ethanol under ultrasonic irradiation. Owing to higher yields, shorter reaction times, lower temperatures and ease of operation, the ultrasonic irradiation approach is an eco-friendly alternative process to the conventional formation of pyrazoline analogues.

4.1j Pyrazole-4-carbonitriles formation in aqueous bath with copper(II) oxide in zirconium dioxide: Maddila et al., reported an eco-friendly and well-organized one-pot three-component process for the formation of pyrazole-4-carbonitirile analogues $\mathbf{5 4}$ via reaction of 
<smiles>[R]CC(=O)CC(=O)OCC</smiles>

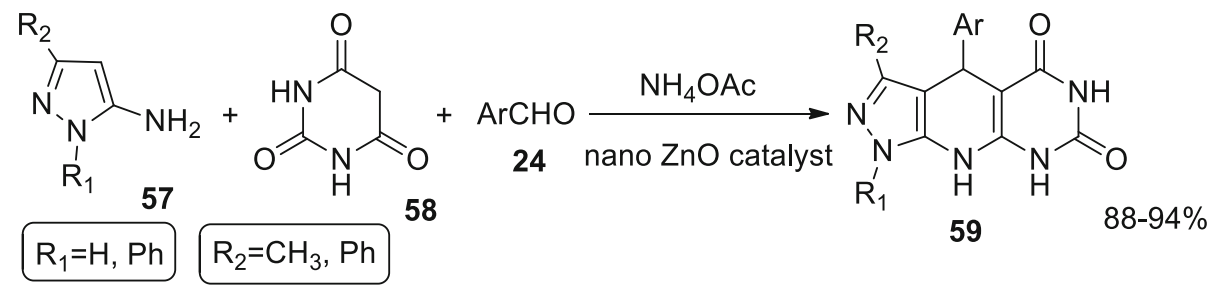
$\mathrm{Ar}=\mathrm{C}_{6} \mathrm{H}_{5} ; 4-\mathrm{FC}_{6} \mathrm{H}_{4} ; 4-\mathrm{ClC}_{6} \mathrm{H}_{4} ; 4-\mathrm{BrC}_{6} \mathrm{H}_{4} ; 4-\mathrm{NO}_{2} \mathrm{C}_{6} \mathrm{H}_{4} ; 3-\mathrm{NO}_{2} \mathrm{C}_{6} \mathrm{H}_{4} ; 2,4-\mathrm{ClC}_{6} \mathrm{H}_{3} ; 4-\mathrm{OHC} \mathrm{H}_{4} ; 4-\mathrm{N}(\mathrm{Me})_{2} \mathrm{C}_{6} \mathrm{H}_{4}$

Scheme 11. Formation of pyrido[2,3- $d]$ pyrimidine-dione derivatives.

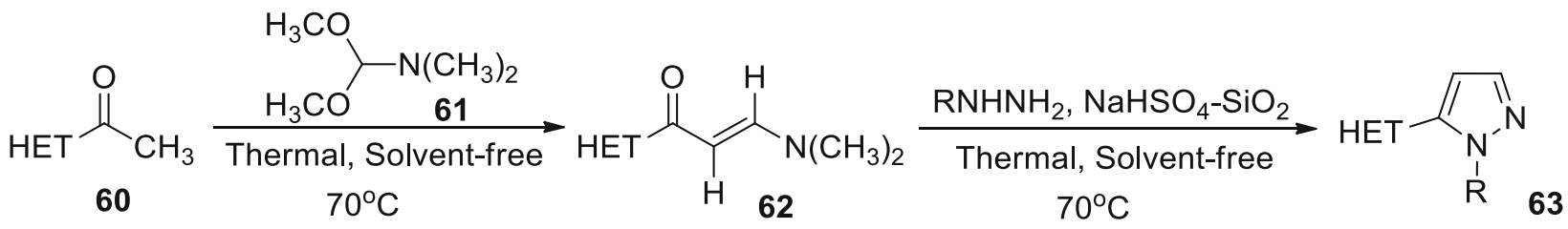<smiles>Cc1cc(O)c(C(=O)O)c(=O)oc1=O</smiles>

Scheme 12. Synthesis of pyrazoles using $\mathrm{NaHSO}_{4}-\mathrm{SiO}_{2}$.

malononitrile 23, aldehydes $\mathbf{2 4}$ and phenyl hydrazine 53 in the presence of copper(II) oxide in zirconium dioxide $\left(\mathrm{CuO} / \mathrm{ZrO}_{2}\right)$ as a catalyst in water as reaction medium (Scheme 10). The catalyst is recyclable for over five runs, without affecting its outstanding potency. This recyclable and simple heterogeneous catalytic system, $\mathrm{CuO}$ in $\mathrm{ZrO}_{2}$, displayed an extraordinary catalytic affinity for MCR approach. The existing methodology deals with numerous benefits, for instance, short reaction times, good to high yields, purity of products, simple workup, cost-effectiveness, need of environmentally benign green solvents and a small amount of inexpensive catalysts. This technique reveals to be a favorable environmentally benign method for the preparation of a series of pyrazole analogues. ${ }^{48}$

$4.1 \mathrm{k}$ A multi-component aqueous preparation of pyrido[2,3-d]pyrimidine-dione derivatives: A unique one-pot preparation of pyrazolo[41,31:5,6]pyrido[2,3d]pyrimidine-diones $\mathbf{5 9}$ (pyrazole-based pyrido[2,3$d$ ]pyrimidine-dione derivatives) via a five-component aqueous reaction has been disclosed by Heravi et $a l .{ }^{49}$ The aqueous reaction of acetoacetic ester $\mathbf{5 5}$ and hydrazine monohydrate $\mathbf{5 6}$ was rapidly and smoothly proceeded to furnish 3-methyl-5-hydrazolone 57, nearly in quantitative yield. Next, in the same flask, the synthesized 3-methyl-5-hydrazolone $\mathbf{5 7}$ was reacted with other three components (ammonium acetate, aryl aldehydes $\mathbf{2 4}$ and 1,3-dimethyl barbituric acid 58) to furnish a five-component reaction and affords pyrazole derivatives 59 (Scheme 11). The whole process was catalyzed by nano $\mathrm{ZnO}$ catalyst in water. The notable advantages of this method are short times of reaction, good yields, simple workup, and environmental benignancy.

\subsection{Utilization of silica supported sodium bisulfate} for pyrazoles synthesis: An effective and useful process for the preparation of library of pyrazole analogues 63 under solvent-free thermal conditionsvia heterocyclic-enaminones using $\mathrm{SiO}_{2}-\mathrm{NaHSO}_{4}$ (sodium bisulfate supported on silica) as an efficient catalyst has been described by Siddiqui et al. ${ }^{50}$ This approach demonstrates very striking features such as economic 

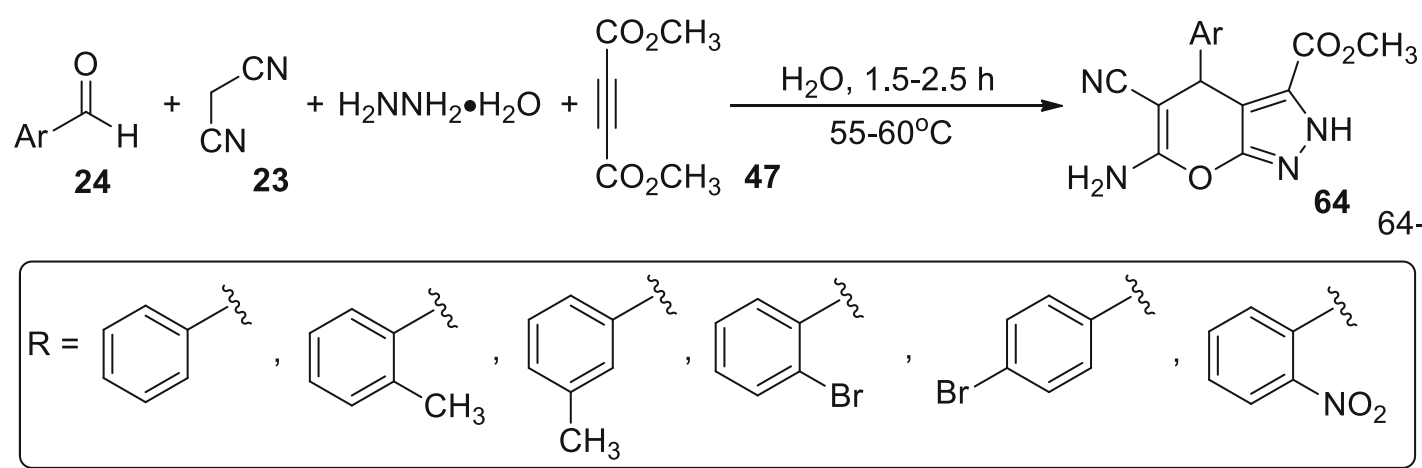

Scheme 13. Multi-component aqueous pyrazoles synthesis.

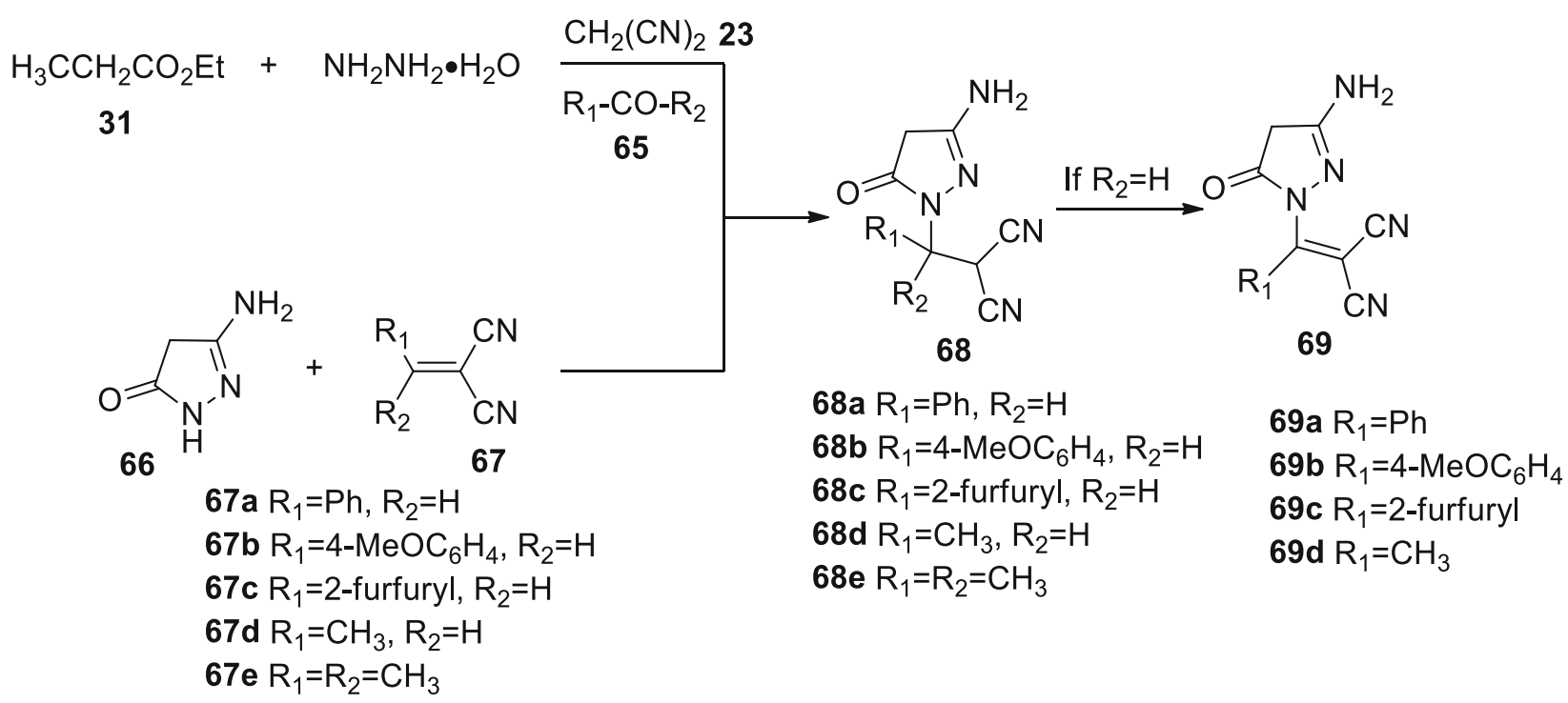

Scheme 14. Multi-component reaction to furnish pyrano[2,3-c]-pyrazole derivatives.

viability, simple work-up and reasonable yields of the pyrazoles (Scheme 12). The catalyst can be reused various times without important loss of its catalytic potency.

$4.1 \mathrm{~m}$ Four-component one-pot reaction in aqueous media for pyrazole cores formation: A green, fourcomponent, catalyst-free and one-pot formation of methyl 6-amino-5-cyano-4-aryl-2,4-dihydropyrano [2,3-c]pyrazole-3-carboxylate derivatives 64 in aqueous media is described by Adeleh Moshtaghi Zonouz et $a l .{ }^{51}$ The four-component were aldehyde, malononitrile, hydrazine and dimethyl but-2-ynedioate (Scheme 13). The technique does not include any tedious purification or work-up and is atom-economical, catalyst-free and affords the target pyrazoles in reasonable yields.

4.1n One-pot eco-friendly solvent-less procedure for pyrano[2,3-c]-pyrazoles synthesis: Convenient multicomponent synthesis of pyrazoles is disclosed by AlMatar et al. ${ }^{52}$ In this approach, synthesis of pyrano[2,3c]pyrazole derivatives 69 were accomplished through the mixing of hydrazine monohydrate, malononitrile 23, ethyl acetoacetate 31, and ketones or aldehydes $\mathbf{6 5}$ in the solvent-free conditions (Scheme 14). Alternatively, the reaction of aminopyrazolones $\mathbf{6 6}$ with arylidenemalononitrile 67 afforded pyrano[2,3-c]pyrazoles 69. The yields in multi-component synthetic approach were observed to be nearly identical to those of previously reported synthetic methodologies in this book chapter but they are highly greener, avoiding the utilization of solvent, purification and separation steps. Chitosan could be employed as a catalyst for the reaction by replacing the use of homogeneous catalyst. The mild conditions applied as well as the high yields obtained are significant features of the reaction. This method avoids the use of tedious workup and column chromatographic purification of products, making the method expedient and superior.

4.1o Organo-nanocatalyst: magnetically retrievable iron oxide-anchored GSH for MW-mediated pyrazoles synthesis: Polshettiwar et al., developed a unique 


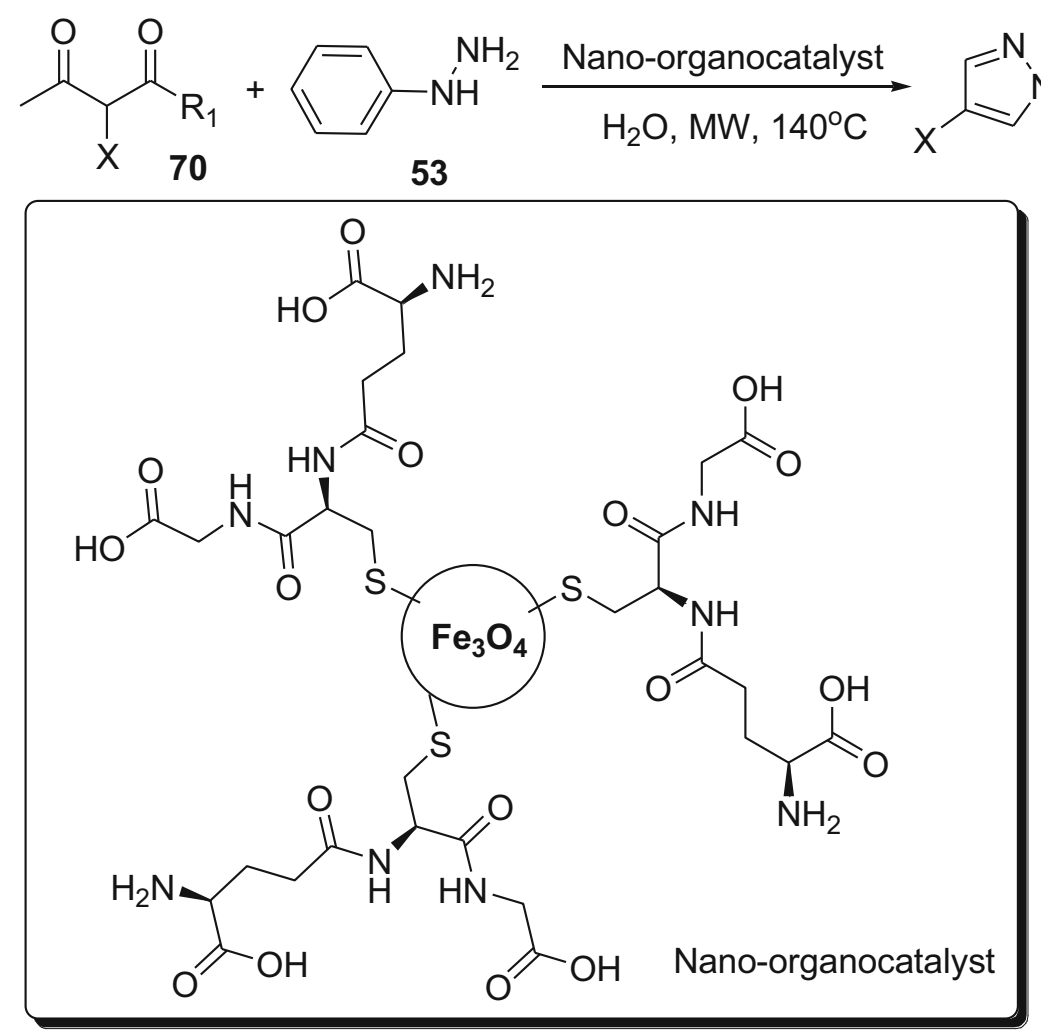

Scheme 15. Organo-nanocatalyst microwave-assisted pyrazoles synthesis.
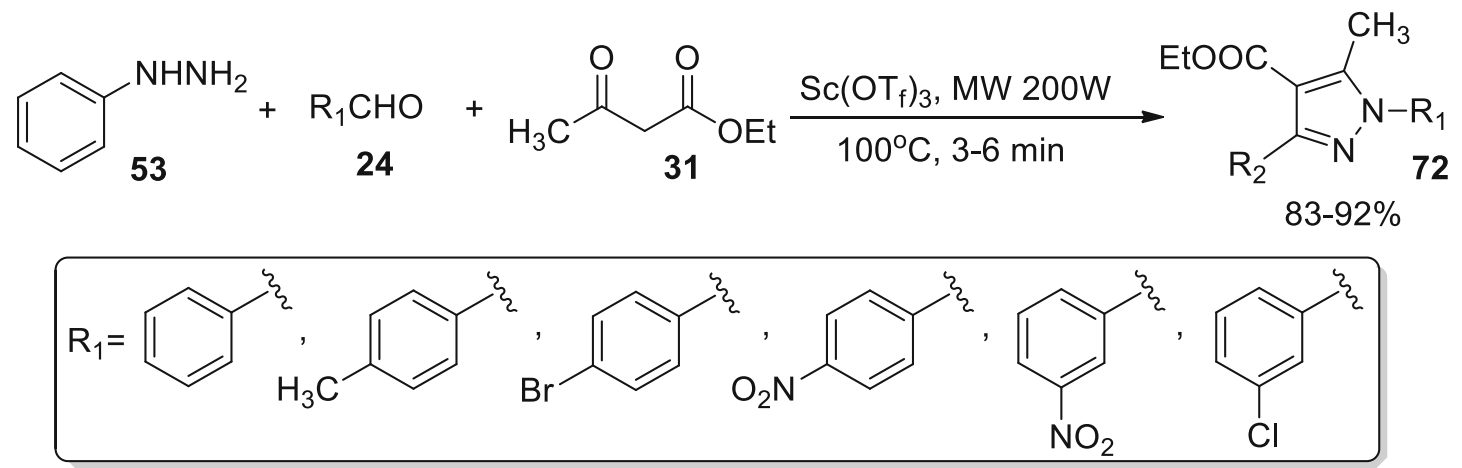

Scheme 16. Scandium triflate-catalyzed formation of functionalized pyrazoles.

concept of organo-nanocatalyst, by supporting totally benign and environmentally abundant glutathione (GSH) on magnetic nanocatalyst. ${ }^{53}$ Post-synthetic modification of magnetic NPs surface by GSH imparts required chemical functionality and allows the catalytic site's formation on the exteriors of ensuing organocatalysts. The catalyst displayed an outstanding affinity for microwave (MW)-assisted pyrazoles synthesis. The reaction of $\mathbf{7 0}$ with $\mathbf{5 3}$ in the existence of organonanocatalyst in aqueous medium under MWI afforded pyrazoles 71 in 78-98\% (Scheme 15). This innovative organo-nanocatalyst bridges the gap between heterogeneous and homogeneous catalysis; therefore, preserving the required attributes of both the synthetic systems.
Their paramagnetic nature coupled with an insoluble character allows easy isolation of these nanoparticles from the reaction contents using bar magnet, which minimizes the prerequisite catalyst separation by filtration.

\section{1p Scandium triflate-catalytic system for pyrazoles} synthesis under MWI: An eco-friendly, rapid and effective formation of functionalized pyrazole derivatives 72 under solvent-less conditions by the treatment of aldehydes $\mathbf{2 4}$ with acetoacetic ester $\mathbf{3 1}$ and phenyl hydrazine $\mathbf{5 3}$ has been reported by Kumari et al. ${ }^{54}$ This methodology exploits the synthetic potential of MWI and scandium(III) triflate $\mathrm{Sc}\left(\mathrm{OT}_{\mathrm{f}}\right)_{3}$ combination and illustrates numerous benefits such as easy isolation of 


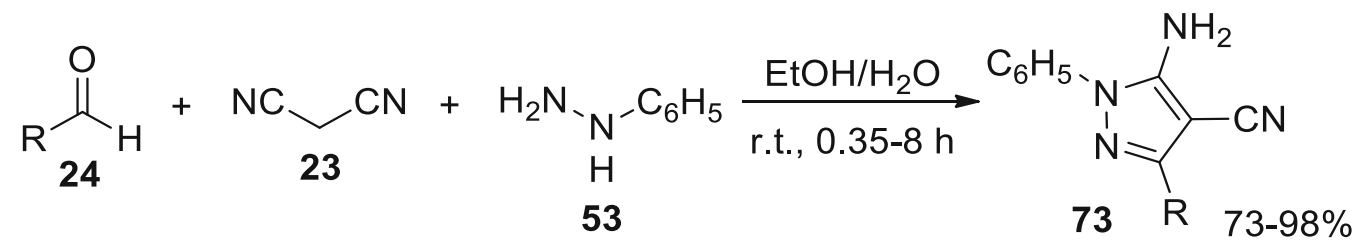

$$
\begin{gathered}
\mathrm{R}=\mathrm{C}_{6} \mathrm{H}_{5} ; 4-\mathrm{Me}-\mathrm{C}_{6} \mathrm{H}_{5} ; 2-\mathrm{OH}-\mathrm{C}_{6} \mathrm{H}_{5} ; 4-\mathrm{Cl}-\mathrm{C}_{6} \mathrm{H}_{5} ; 4-\mathrm{NO}_{2}-\mathrm{C}_{6} \mathrm{H}_{5} ; 3-\mathrm{NO}_{2}-\mathrm{C}_{6} \mathrm{H}_{5} ; \\
2-\mathrm{NO}_{2}-\mathrm{C}_{6} \mathrm{H}_{5} ; 4-\mathrm{CN}-\mathrm{C}_{6} \mathrm{H}_{5} ; 4 \text {-isopropyl- } \mathrm{C}_{6} \mathrm{H}_{5} ; 3,4-\text { di-MeO- }-\mathrm{C}_{6} \mathrm{H}_{5} ; 2 \text {-thienyl }
\end{gathered}
$$

Scheme 17. Development of poly-substituted amino-pyrazole systems.

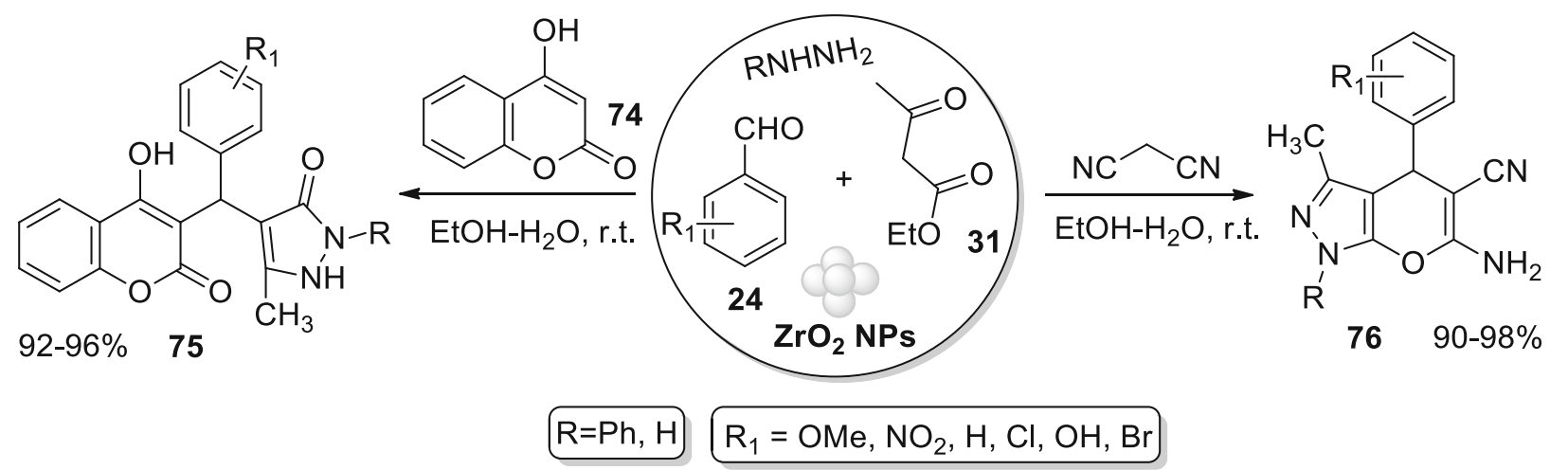

Scheme 18. Application of zirconium dioxide NPs as a nanocatalyst for construction pyrazoles.

products, shorter reaction times, eco-friendly reaction conditions and excellent product yields (Scheme 16).

4.1q Multi-component green media formation of 5amino-1,3-aryl-1H-pyrazole-4-carbonitriles: Hasaninejad et al., disclosed a convenient and novel threecomponent one-pot approach for the preparation of poly-substituted amino-pyrazoles $\mathbf{7 3}$ via a tandem cyclo-Knoevengel condensation of malononitrile 23, aryl-aldehydes 24, and phenyl hydrazine $\mathbf{5 3}$ in $\mathrm{H}_{2} \mathrm{O}$ and $\mathrm{EtOH}$ at r.t. ${ }^{55}$ This multi-component catalyst-free methodology smoothly proceeded in reasonable yields and illustrates numerous other benefits i.e., no toxic by-products, simple work-up experimental procedures and short reaction times (Scheme 17). The method also eliminates the application of anhydrous conditions, toxic organic solvents and catalysts. This procedure signifies a promising eco-friendly pathway for the construction of poly-substituted amino-pyrazole systems 73.

4.1r Benzylpyrazolyl coumarins and pyrano[2,3-c] pyrazoles synthesis using zirconium dioxide NPs: A one-pot novel multi-component procedure for the development of bio-active benzylpyrazolyl coumarin derivatives $\mathbf{7 5}$ and pyrano[2,3-c]pyrazole derivatives $\mathbf{7 6}$ has been reported by Saha et al., using $\mathrm{ZrO}_{2}$ (zirconium dioxide) nanoparticles (NPs) as a nanocatalyst at r.t. ${ }^{56}$ The reactions were high yielding and very fast
(Scheme 18). The tetragonal plane of the zirconium dioxide NPs and catalytic potency remained unaffected after the tenth recycle. The process by Saha et al., is eco-friendly as the nanocatalyst is reusable and nontoxic, reactions were accomplished at $25{ }^{\circ} \mathrm{C}$ in a green solvent (ethanol-water); pyrazoles were decontaminated through recrystallization from EtOH, and chromatographic purification was not desired by this scheme; hence, the application of hazardous and volatile solvents has also been circumvented.

4.1s Polyfunctionalized pyrano[2,3-c]pyrazole systems synthesis through BMIMB $F_{4}$ ILs: A rapid, ecofriendly and highly effective production of $4 \mathrm{H}$-pyrano [2,3-c]pyrazoles 77 using multi-component cyclocondensation of phenyl hydrazine/hydrazine monohydrate, malononitrile 23, aryl-aldehydes $\mathbf{2 4}$ and acetoacetic ester $\mathbf{3 1}$ in the presence of IL 1-butyl-3-methylimidazolium tetrafluoroborate and L-proline at r.t. has been disclosed by Khurana et al. ${ }^{57}$ Reusability of the IL without important loss of potency was a chief benefit (Scheme 19).

4.1t Grinding induced formation of highly substituted pyrazoles: Grinding induced formation of highly substituted pyrazoles $\mathbf{8 0}$ by application of malononitrile 23, phenylhydrazine 53 and functionalized aldehydes 78 has been disclosed by Madhulika Srivastava et al. ${ }^{58}$ In this process, IL 79 is utilized as a catalyst with $\mathrm{H}_{2} \mathrm{O}$ 

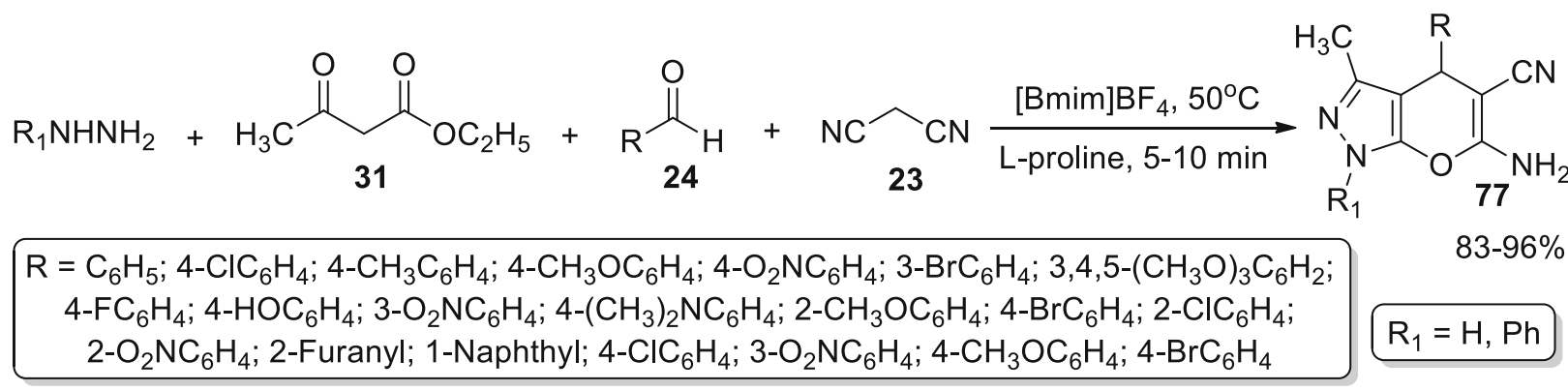

Scheme 19. IL-based multi-component preparation of pyrano[2,3-c]pyrazoles.
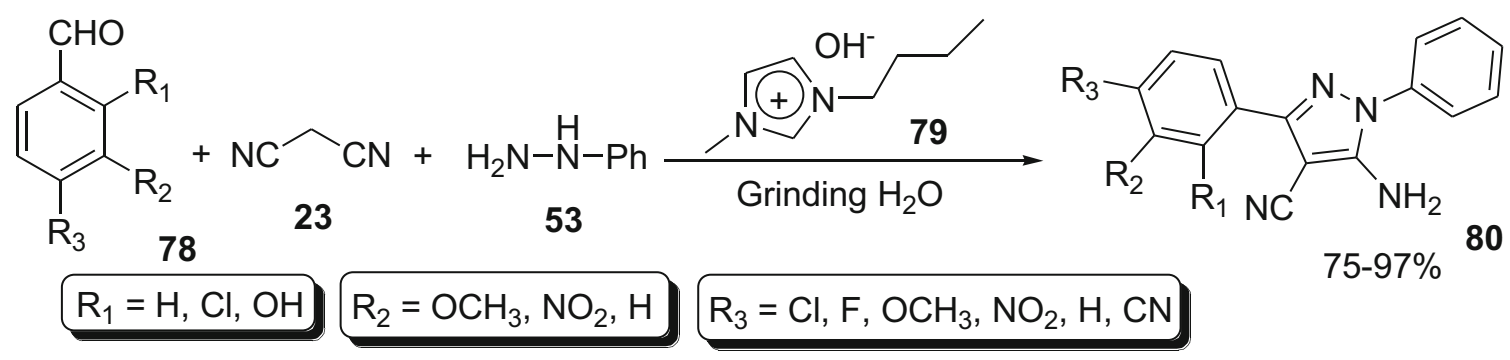

Scheme 20. IL mediated formation of highly substituted pyrazoles.

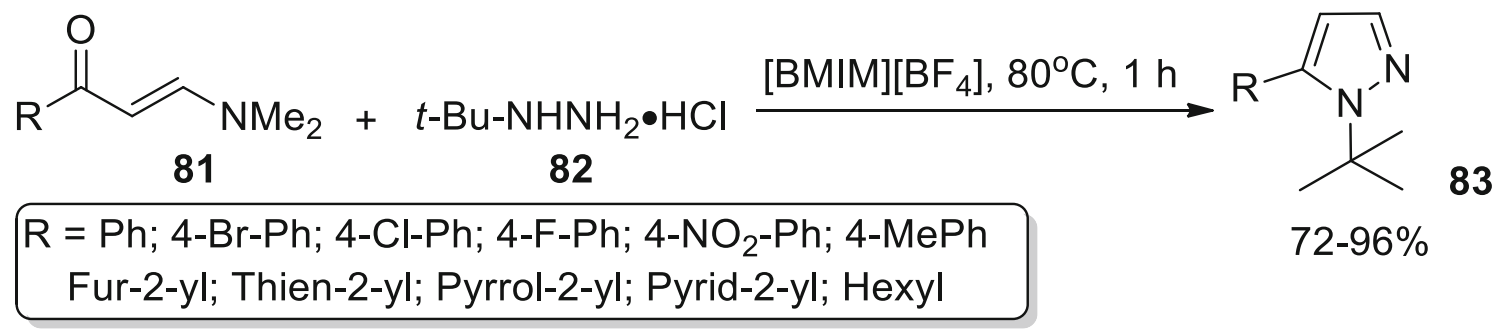

Scheme 21. Synthesis of pyrazoles by application of the IL [BMIM] $\left[\mathrm{BF}_{4}\right]$.

and no byproducts were formed (Scheme 20). Most importantly, simple handling and attainment of high yield up to $97 \%$ are the advantages of this methodology.

4.1u Synthesis of tert-butylpyrazoles by using ionic liquid: This approach is reported by Clarissa $\mathrm{P}$. Frizzo et al. In his report, investigations on different ionic liquids, ([HMIM] $\left[\mathrm{CF}_{3} \mathrm{CO}_{2}\right]$, [HMIM] $\left[\mathrm{HSO}_{4}\right]$, [BMIM][SCN], [BMIM] $[\mathrm{OH}], \quad[\mathrm{DBMIM}]\left[\mathrm{BF}_{4}\right]$, [DBMIM] [Br], [BMIM] $\left[\mathrm{PF}_{6}\right],[\mathrm{OMIM}]\left[\mathrm{BF}_{4}\right],[\mathrm{BMIM}]$ $[\mathrm{Br}]$ and $[\mathrm{BMIM}]\left[\mathrm{BF}_{4}\right]$ ) were performed. The results of the investigation revealed that ionic liquid [BMIM] $\left[\mathrm{BF}_{4}\right]$ provides the highest efficiency for cyclocondensation reactions. The cyclocondensation reaction between 4dimethylamino-1-phenyl-3-alken-2-one derivatives $\mathbf{8 1}$ and tert-butylhydrazine $\mathbf{8 2}$ in the existence of ionic liquid $[\mathrm{BMIM}]\left[\mathrm{BF}_{4}\right]$ afforded tert-butylpyrazoles $\mathbf{8 3}$ in excellent yields. ${ }^{59}[\mathrm{BMIM}]\left[\mathrm{BF}_{4}\right]$ IL was also observed to be an efficient, fast and mild approach for the regioselective preparation of tert-butylpyrazoles $\mathbf{8 3}$

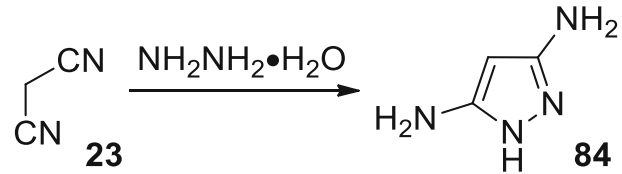

Scheme 22. Synthesis of 3,5-diaminopyrazole.

(Scheme 21). This technique permitted the formation of a series of new pyrazole derivatives that are problematic to prepare by other techniques.

\subsection{Well-known classical approaches to construct important pyrazole derivatives}

4.2a Synthesis of 5-amino-3-(cyanomethyl)-1H-pyrazol-4-yl cyanide: Using the $1^{\text {st }}$ attempt in 1894, Rothenburg suggested that malononitrile $\mathbf{2 3}$ can be treated with hydrazine monohydrate to afford $1 \mathrm{H}$ pyrazole-3,5-diamines 84 (Scheme 22). Von Rothenburg failed to observe that the formation $1 H$-pyrazole3,5-diamine 84 was completed through the release of ammonia. ${ }^{60,61}$ 

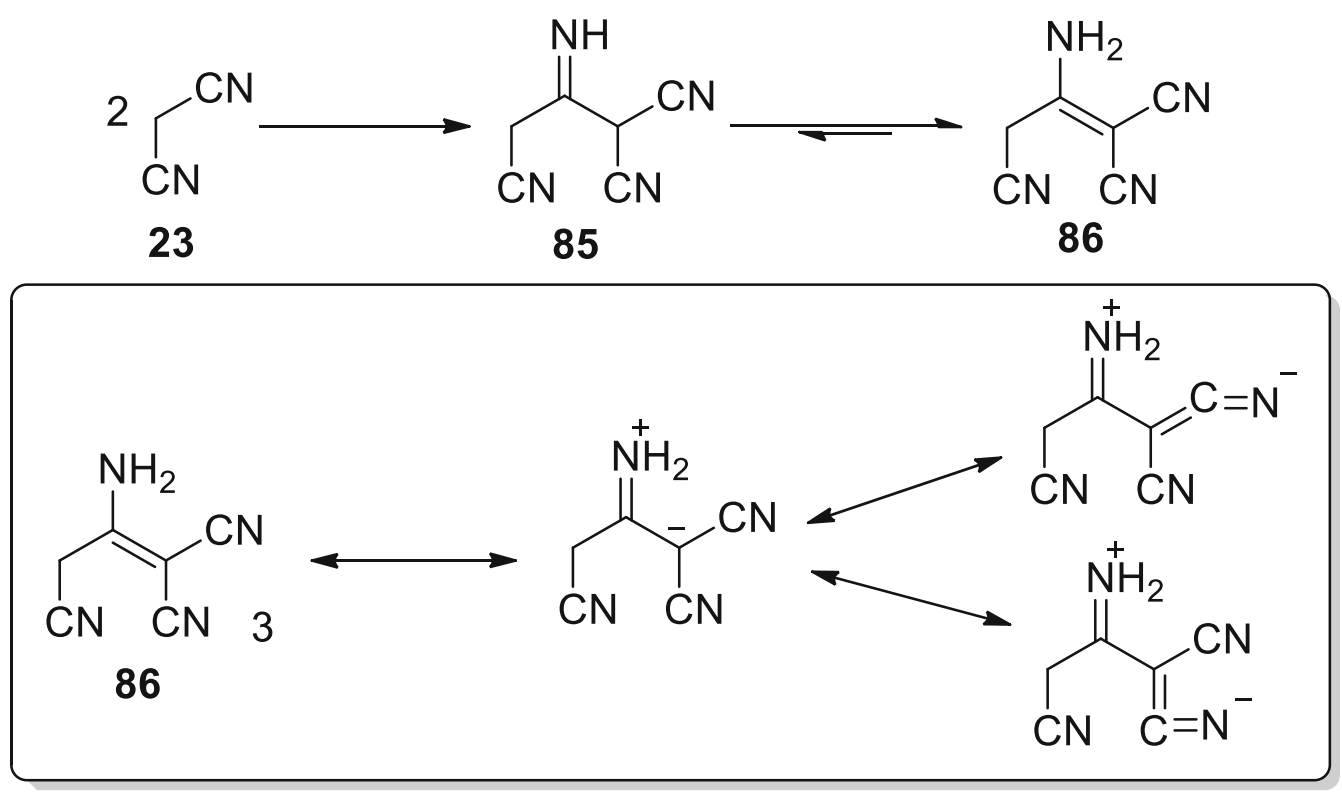

Scheme 23. Formation of malononitrile dimer.

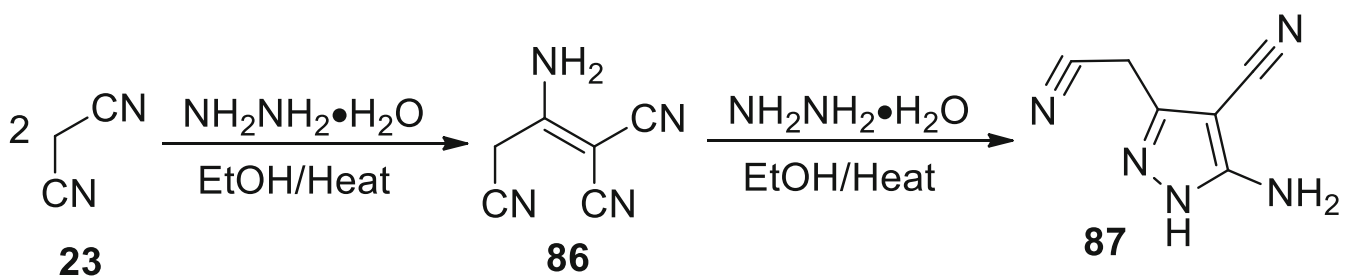

Scheme 24. Synthesis of 5-amino-3-(cyanomethyl)-1H-pyrazol-4-yl cyanide.

After some years, co-workers have demonstrated that the product was already $\mathbf{8 7}$ produced through the process of malononitrile $\mathbf{2 3}$ dimerisation to furnish dimer of malononitrile (2-aminoprop-1-ene-1,1,3tricarbonitrile) 86 (Scheme 23). ${ }^{62}$ The mechanism of reaction proposed that the elimination of $\mathrm{a} \mathrm{H}^{+}$from the activated methylene moiety in malononitrile $\mathbf{2 3}$ and subsequent nucleophilic addition of this anion to the unsaturated carbon of a $2^{\text {nd }}$ malononitrile entity $\mathbf{2 3}$ affords a 2-iminopropane-1,1,3-tricarbonitrile $\mathbf{8 5}$ which would readily rearrange to the more stabilized form 86. ${ }^{63}$ Compound $\mathbf{8 6}$ appears as one of the numerous zwitterionic structures stabilized by election delocalization (Scheme 23).

The reaction of malononitrile dimer $\mathbf{8 6}$ or malononitrile 23 with hydrazine hydrate provided 5-amino-3-(cyanomethyl)-1H-pyrazol-4-yl cyanide $\mathbf{8 7}$ (Scheme 24). ${ }^{64,65}$

The product was synthesized from one mole of hydrazine monohydrate and two moles of malononitrile 23 with the elimination of one mole of $\mathrm{NH}_{3}$ to produce 87 in $40 \%$ yields. The best method was the reaction of a dimer of malononitrile $\mathbf{8 6}$ with hydrazine monohydrate to provide 87 in $71.5 \%$ (Scheme 24). The mechanism of the reaction for the synthesis of pyrazoles involves Michael addition in which hydrazine hydrate attacks the $\alpha, \beta$-unsaturated system of malononitrile dimer as intermediate and cyclizes to give pyrazole $\mathbf{8 7}$.

4.2b Synthesis of azo dyes of pyrazole: Azo dyes are prepared through two-step reactions, i.e., diazotization and coupling reactions. Diazotization involves treatment of a primary aromatic amino group of pyrazole analogues with nitrous acid to afford an aromatic diazonium ion; the next step is the coupling of the diazonium salt of pyrazole analogues with a nucleophilic compound in baseline conditions. Active methylene compounds are very beneficial because they act as intermediates in organic synthesis; they show different reactions, for example, Knoevenagel condensation and synthesis of azo dyes, on account of the acidic hydrogens in the active methylene group that could copulate with a number of aminoaromatic compounds to configure numerous hydrazones. Diazonium salts of pyrazole analogues couple with active hydrogen-containing reagents mainly ethyl acetoacetate, ethyl cyanoacetate, malononitrile, acetylacetone, pyrazole derivatives and pyrazolones and yield the corresponding azo derivatives 


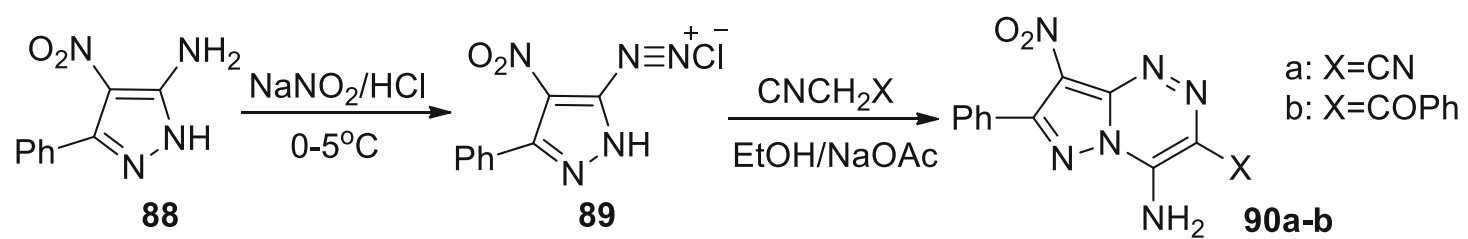

Scheme 25. Formation of pyrazolo[5,1-c]-1,2,4-triazines.

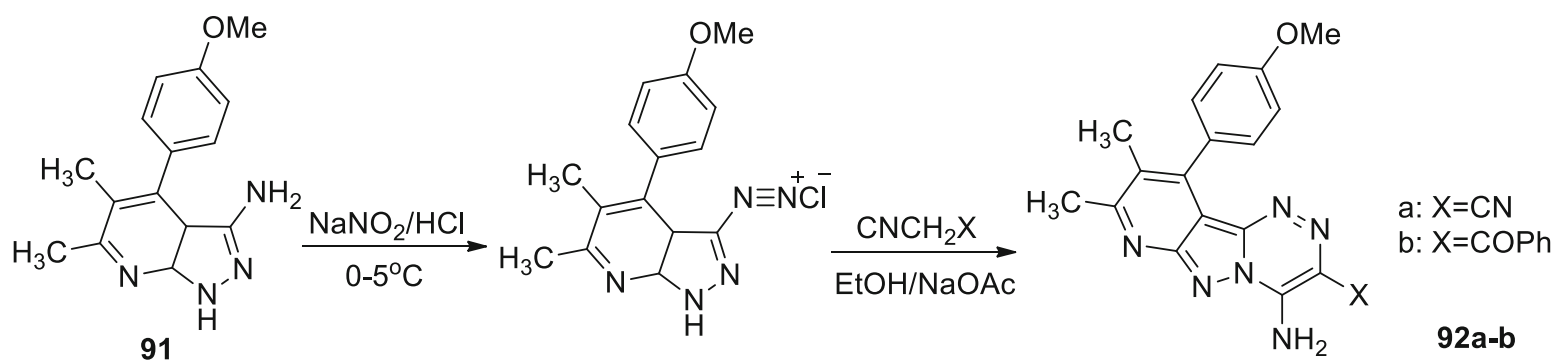<smiles>CCOC(=O)c1nnc2c(N=N[Ga])c(N)nn2c1C</smiles>

Scheme 26. Formation of pyrazolo[5,1-c]1,2,4-triazines.

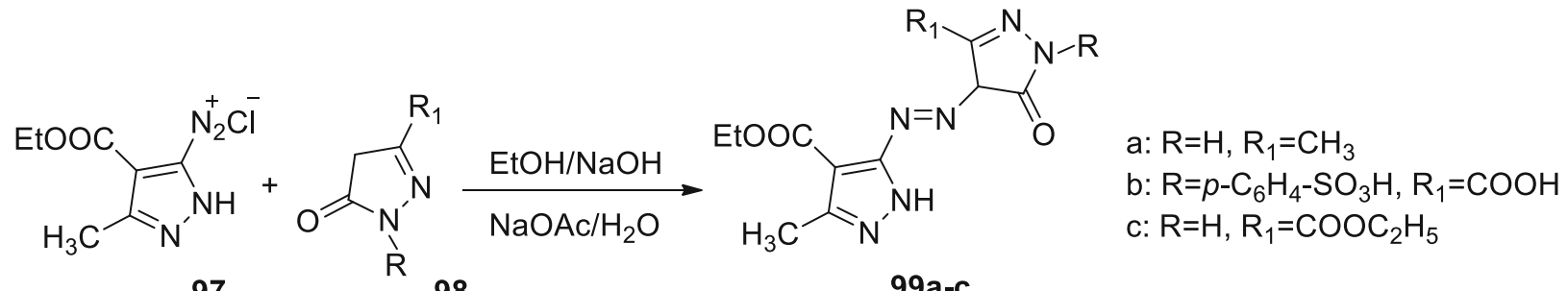
97 98 99a-c<smiles></smiles>

Scheme 27. Synthesis of hydrazone derivatives.

or lead to the development of the pyrazolo[1,5-c] as-triazines, ${ }^{66,67}$ through cyclocondensation reaction, that takes place by nucleophilic attack of nitrogen atom of pyrazole on the electrophilic group in active hydrogen reagents.

In 1989, triazine analogues were formed directly under the same reaction conditions by coupling 5amino-3-phenyl-4-nitropyrazole $\mathbf{8 8}$ with malononitrile and benzoylacetonitrile reagents, the resulting compound was readily cyclized to yield pyrazolo[5,1c]-1,2,4-triazines 90a-b, respectively (Scheme 25). ${ }^{68}$
Also, malononitrile and benzoylacetonitrile could easily be coupled with the amino compound 91, the resulting compound can readily be cyclized via stirring under the same conditions of coupling reaction to afford 92a-b, respectively (Scheme 26). ${ }^{69}$ The coupling of Diazonium salt of arylazopyrazole 94 with malononitrile and ethyl acetoacetate yielded directly the pyrazolo[5,1-c]1,2,4-triazines 93 and 95 (Scheme 26). ${ }^{70}$

Diazotization of 4-(ethoxycarbonyl)-3-methyl-1Hpyrazole-5-diazonium chloride $\mathbf{9 7},{ }^{71}$ on reaction with mono and 1,3-disubstituted pyrazolones $\mathbf{9 8}$ produced 


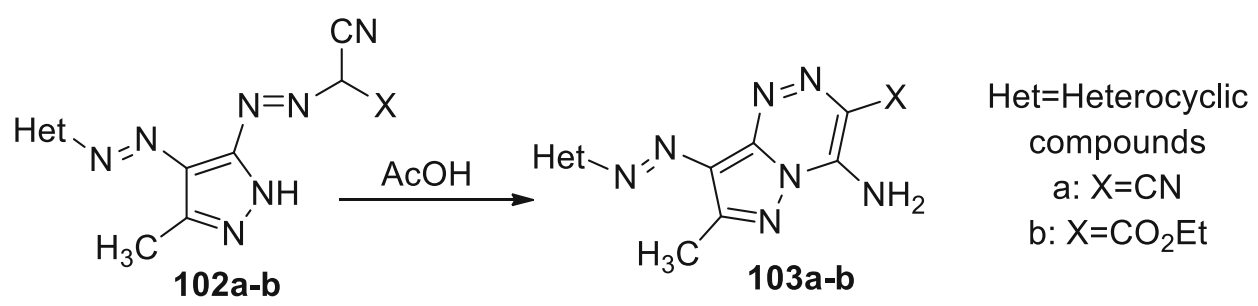<smiles></smiles><smiles>N#CCC(=O)Nc1n[nH]c(N=Nc2c(N)n[nH]c2N=Nc2ccccc2)c1N=Nc1c(N)n[nH]c1N=Nc1ccccc1</smiles>

Scheme 28. Synthesis of triazine dye, pyrazolone dye and hydrazone derivative.<smiles>CC(C)(O)c1ccccc1</smiles>

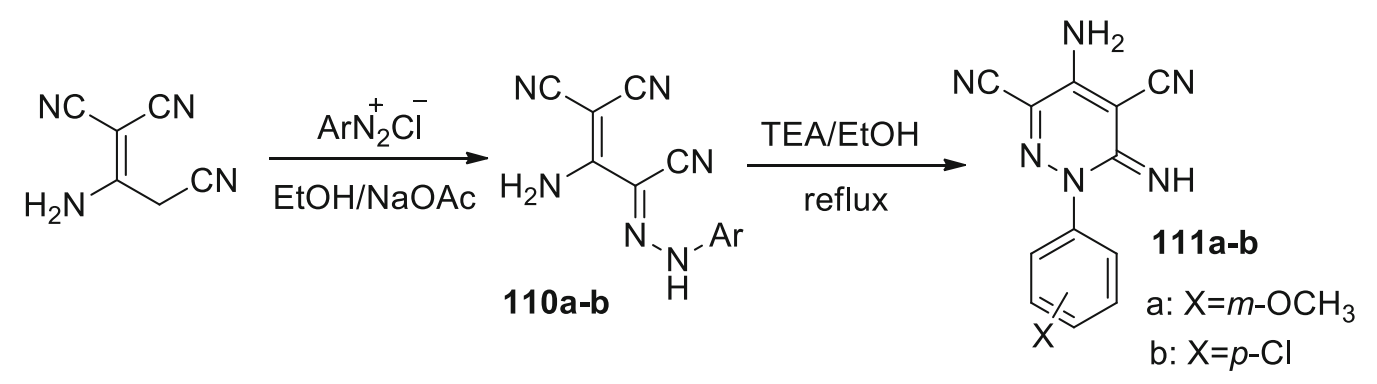

Scheme 29. Formation of pyridazinimine derivatives.

three tautomeric forms of compound 99a-c, as well as cyclization possibilities in good yields of $85 \%$ (Scheme 27). Hydrazone derivative 101 was formed through the conversion of 3-aminopyrazole $\mathbf{1 0 0}$ into diazonium salts, followed by coupling with 3-amino1H-pyrazol-5(4H)-one in pyridine as solvent (Scheme 27). ${ }^{72}$

Fati and Fikret ${ }^{73}$ reported the ten unique dyes viz., pyrazolo[5,1-c] [1,2,4]triazines $\mathbf{1 0 3 a - b}$, prepared by refluxing ethyl pyrazolylazo cyanoacetate $\mathbf{1 0 2} \mathbf{b}$ and pyrazolylazo malononitrile 102a in glacial $\mathrm{AcOH}$. Whereas, coupling reaction of 5-amino-3-methyl-4-
heterylazo-1H-pyrazole 104 with 3-methyl-1H-pyrazole-5(4H)-one produced pyrazolone dye $\mathbf{1 0 5}$, without cyclization attempt/step (Scheme 28). ${ }^{74}$ Pyrazolyl diazonium chloride $\mathbf{1 0 6}$ has been coupled with the active methylene group of cyanoacetanilide and affords the corresponding hydrazone derivative 107. ${ }^{75}$

Also, the cyclocondensation reaction was completed when compound $\mathbf{1 0 8}$ was refluxed with acetic acid. The reaction mechanism occurs via nucleophilic attack of the ring nitrogen atom on the electrophilic cyano group in the compound to yield $\mathbf{1 0 9}$ (Scheme 29). ${ }^{76}$ Malononitrile dimer reacts with different aryldiazonium chlorides 

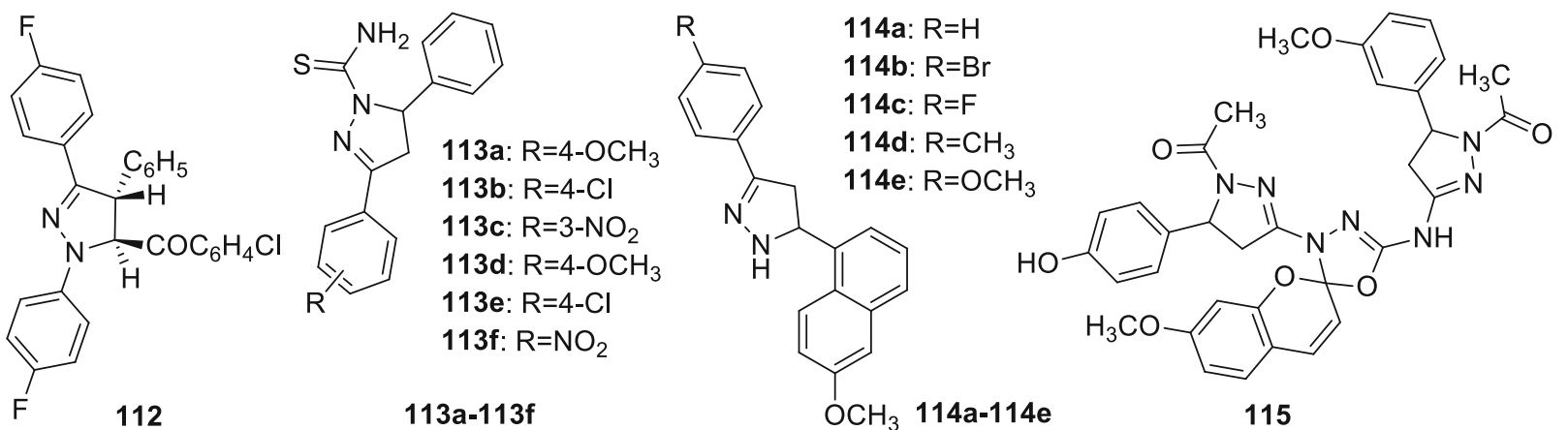

Figure 7. Structures of pyrazole-based potent anti-bacterial compounds.

Table 2. Antimicrobial activity-sensitivity testing of compounds (113a-113f and 114-114e).

\begin{tabular}{|c|c|c|c|c|c|c|c|}
\hline \multirow[t]{3}{*}{ Compound } & \multicolumn{7}{|c|}{ Zone of inhibition in $\mathrm{mm}$} \\
\hline & \multicolumn{5}{|c|}{ Antibacterial activity } & \multicolumn{2}{|c|}{ Antifungal activity } \\
\hline & S. aureus & B. subtilis & E. coli & P. aeruginosa & Salmonella typhi & C. albicans & A. niger \\
\hline 113a & 10 & 11 & 8 & 8 & N.R & 22 & 24 \\
\hline 113b & 13 & 15 & 9 & 9 & N.R & 23 & 26 \\
\hline $113 c$ & 10 & 12 & 8 & 9 & N.R & 19 & 22 \\
\hline 113d & 12 & 13 & 9 & 9 & N.R & 26 & 22 \\
\hline 113e & 11 & 10 & 9 & 9 & N.R & 17 & 20 \\
\hline $113 f$ & 10 & 9 & 8 & 8 & N.R & 17 & 20 \\
\hline 114a & 14 & 12 & 9 & N.R & 11 & N.R & N.R \\
\hline 114b & 26 & 17 & 14 & N.R & 18 & N.R & N.R \\
\hline $114 c$ & 28 & 19 & 15 & N.R & 20 & N.R & N.R \\
\hline 114d & 23 & 13 & 11 & N.R & 14 & N.R & N.R \\
\hline $114 \mathrm{e}$ & 19 & 15 & 10 & N.R & 11 & N.R & N.R \\
\hline
\end{tabular}

$\mathrm{N} . \mathrm{R}=$ not reported.

to give pyridazine derivatives that are found to be good intermediates for the formation of fused heterocycles. ${ }^{55}$ The reaction of MND with diazonium chloride salts of aniline derivatives yields intermediate substituted arylhydrazones $\mathbf{1 1 0 a}-\mathbf{b}$, that readily cyclizes in basic medium providing pyridazinimine derivatives 111a-b (Scheme 29). ${ }^{77}$

\section{Overview of biological potency of pyrazole containing compounds}

Pyrazoles are known to be one of the most prominent types of $\mathrm{N}$-containing heterocycles exhibiting large spectrum of biological potencies such as antiinflammatory, anti-cancer, anti-bacterial, anti-microbial, anti-analgesic, anti-tubercular, anti-viral, anthelmintic, antifungal, hypotensive, anti-nociceptive, insecticidal, MAO inhibitory, anti-mycobacterial, antihelmintic, anti-HIV, antitumor, anti-oxidant, ACE-inhibitory, anticonvulsant and antidepressant activities. ${ }^{78-118}$ The following section describes in brief, the biological activities elucidated by the presence of pyrazole moiety in various compounds.

\subsection{Anti-bacterial potency of pyrazole derivatives}

Nada M. Abunada and co-workers prepared 1,3,4,5tetraaryl-2-pyrazoline, pyrrolo[3,4-c]pyrazole-4,6dione and 1,3-diaryl-5-(cyanoaminocarbonyl and ethoxycarbonyl)-2-pyrazoline analogues of pyrazole. ${ }^{78}$ The synthesized derivatives were subjected to investigation for anti-bacterial potency. The compound $\mathbf{1 1 2}$ viz., 1-((4R,5S)-1,3-bis(4-fluorophenyl)-4-phenyl-4,5dihydro-1H-pyrazol-5-yl)-7-chlorohepta-2,4,6-triyn-1one was observed to be active against $S$. aureus and E. coli. R. Antimicrobial screening results of the compound 112 shows that inhibition zones were 12 $\mathrm{mm}, 12 \mathrm{~mm}, 0.0 \mathrm{~mm}$ and $10 \mathrm{~mm}$ for E. coli, $S$. aureus, A. flavus and C. albicans, respectively. Chawla and co-workers prepared 3,5-diphenyl-4,5-dihydro- $1 \mathrm{H}$ pyrazole-1-carbothioamide derivatives 113a-113f by making the use of MWI technology (Figure 7). All the prepared pyrazole derivatives were investigated for anti-microbial potency against two Grampositive strains (Bacillus subtilis and Staphylococcus aureus) and two Gram-negative strains (Pseudomonas aeruginosa and Escherichia coli). ${ }^{79}$ The investigation revealed that derivatives 113a-113f of synthesized compounds 

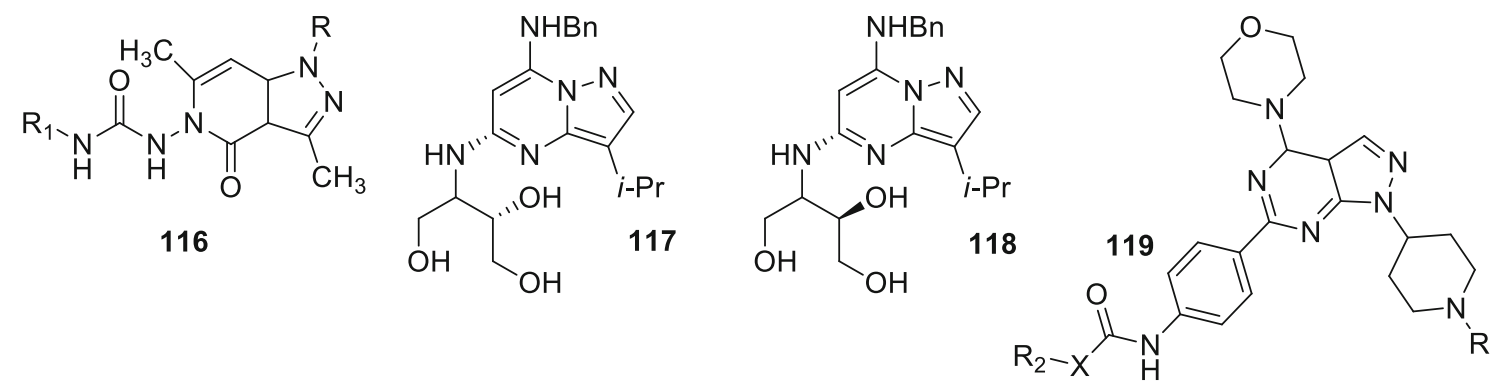

Figure 8. Structures of pyrazole-mediated anti-cancer agents.

Table 3. SAR of the urea and carbamate groups.

\begin{tabular}{|c|c|c|c|c|c|c|c|}
\hline Compound & $\mathrm{R}_{2}$ & $\mathrm{X}$ & $\mathrm{mTOR}^{\mathrm{a}}$ & $\mathrm{PI} 3 \mathrm{~K} \alpha^{\mathrm{a}}$ & Selectivity $^{\mathrm{b}}$ & $\mathrm{LNCap}^{\mathrm{a}}$ & Micros $^{\mathrm{c}}$ \\
\hline $119 a$ & $\mathrm{CH}_{3}$ & $\mathrm{O}$ & $4.3 \pm 0.6$ & $1026 \pm 434$ & 239 & $355 \pm 45$ & $>30$ \\
\hline 119b & $\mathrm{CH}_{2} \mathrm{CH}_{2} \mathrm{OH}$ & $\mathrm{O}$ & $1.0 \pm 0.2$ & $681 \pm 124$ & 681 & $28 \pm 1$ & $>30$ \\
\hline 119c & Et & $\mathrm{NH}$ & $0.32 \pm 0.06$ & $490 \pm 198$ & 1153 & 55 & $>30$ \\
\hline 119d & $\mathrm{CH}_{2} \mathrm{CH}_{2} \mathrm{~F}$ & $\mathrm{NH}$ & $0.61 \pm 0.03$ & $505 \pm 225$ & 828 & $52 \pm 13$ & $>30$ \\
\hline $119 \mathrm{e}$ & $\mathrm{CH}(\mathrm{CH} 2)_{2}$ & $\mathrm{NH}$ & $0.45 \pm 0.04$ & $661 \pm 156$ & 1469 & $42 \pm 3$ & $>30$ \\
\hline 119f & $3-\mathrm{Pyr}$ & $\mathrm{NH}$ & $0.20 \pm 0.01$ & $35 \pm 6$ & 175 & $31 \pm 4$ & 24 \\
\hline $119 \mathrm{~g}$ & $\mathrm{Ph}-4-\mathrm{Pip}-\mathrm{CH}_{3}$ & $\mathrm{NH}$ & $0.30 \pm 0.02$ & 18 & 60 & $60 \pm 15$ & 9 \\
\hline
\end{tabular}

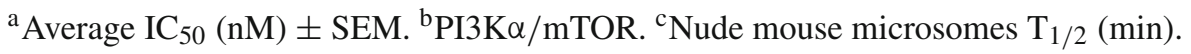

show reasonable anti-bacterial efficacy and noteworthy anti-fungal activity (Table 2). S. B. Jadhav and coworkers synthesized a new library of 5-(6-methoxynaphthalen-1-yl)-3-phenyl-4,5-dihydro-1H-pyrazole analogues 114a-114e (Figure 7). ${ }^{80}$ All the constructed pyrazole derivatives were inspected for their antimicrobial power. All the derivatives demonstrated significant to modest anti-microbial capacity (Table 2). A. Kumar and co-workers synthesized a variety of pyrazole derivatives. ${ }^{81}$ All the newly developed derivatives were evaluated for their anti-bacterial potency against B. sublitis, E. coli, S. aureus and K. pneumonia. All the results were compared with that of ciprofloxacin, which is a standard drug. The most potent anti-bacterial derivative of the series was 115 (Figure 7). In detail, zone of inhibition were 28, 24, 27 and $22 \mathrm{~mm}$ against $K$. pneumoniae, $S$. aureus, E. coli, and B. sublitis, respectively) than standard drug ciprofloxacin.

\subsection{Role of pyrazole derivatives as anti-cancer agents}

Faidallah and co-workers ${ }^{82}$ synthesized some polysubstituted fused pyrazole-based ring systems viz., pyrazolo[4,3-c] pyridines and pyrano[4,3-c]pyrazoles 116 (Figure 8). All the prepared pyrazole derivatives were investigated for anti-microbial and anti-cancer potencies. All the derivatives demonstrated considerable to modest anti-cancer capacity. Dean et al., ${ }^{83}$ synthesized pyrazolo[1,5-a]pyrimidine derived compounds. Among all the derivatives, the compounds 117 and 118 were found to be potent. However, the best results were demonstrated by $\mathbf{1 1 7}$. It was selective CDK inhibitor and significantly inhibit the activities of CDK9, CDK7, CDK5, CDK1 and CDK2 $\left(\mathrm{IC}_{50}=90\right.$, 250, 30, 30 and $3 \mathrm{nmol} / \mathrm{L}$, respectively). Cell-based studies showed inhibition of the phosphorylation of CDK substrates, $\mathrm{Rb}$ and the RNA polymerase II Cterminal domain, down-regulation of cyclins $\mathrm{A}, \mathrm{E}$, and $D 1$, and cell cycle block in the $S$ and $G_{2} / M$ phases. Consistent with these findings, $\mathbf{1 1 7}$ demonstrated potent antiproliferative activity in 60 cancer cell lines tested $\left(\right.$ mean $\left.\mathrm{GI}_{50}=280 \mathrm{nmol} / \mathrm{L}\right)$. Zask et al. ${ }^{84}$ reported the mammalian target of rapamycin pyrazolopyrimidine pyrazole derivatives 119 which were highly potent in anti-cancer activity (Table 3). ${ }^{85,86}$

\subsection{Application of pyrazoles in anti-inflammatory activity}

V. H. Bhaskar and co-workers ${ }^{87}$ prepared various derivatives of 5-phenyl-4-(5-phenyl-4,5-dihydro-1H-pyrazol3 -yl)-4H-1,2,3-triazoles $\mathbf{1 2 0}$ through the reaction of hydrazine monohydrate with chalcones in presence of $\mathrm{AcOH}$. All the prepared derivatives $\mathbf{1 2 0}$ were investigated for anti-inflammatory affinity (Figure 9). The detected increase in anti-inflammatory affinity was 

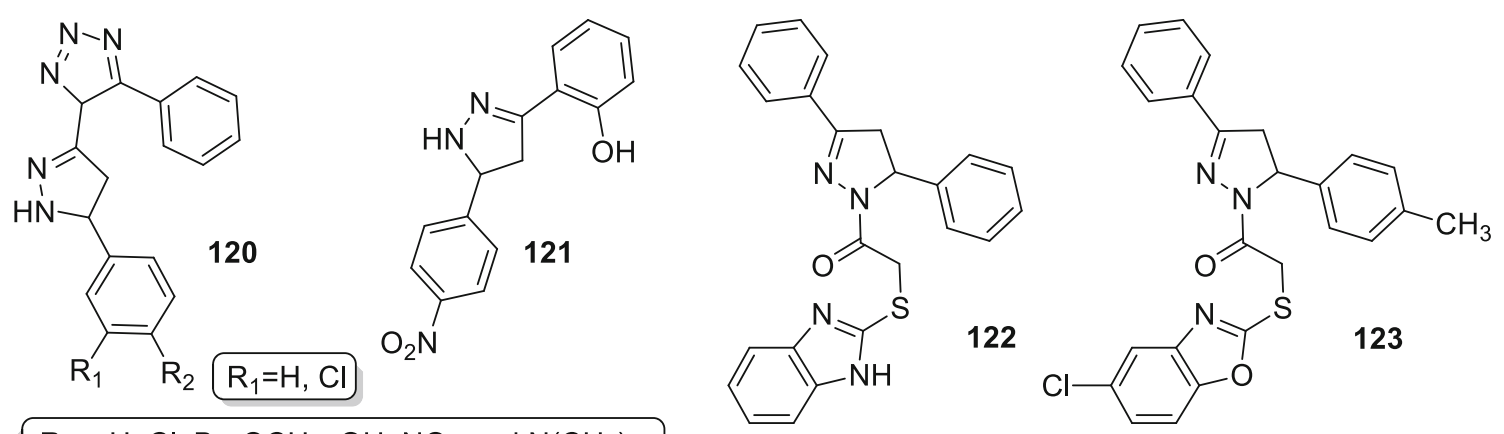

$\mathrm{R}_{2}=\mathrm{H}, \mathrm{Cl}, \mathrm{Br}, \mathrm{OCH}_{3}, \mathrm{OH}, \mathrm{NO}_{2}$ and $\mathrm{N}\left(\mathrm{CH}_{3}\right)_{2}$

Figure 9. Structures of novel anti-inflammatory agents based on pyrazoles.

Table 4. Antibacterial and antifungal data of compounds $120 \mathbf{a}-\mathbf{1 2 0 h}$.

\begin{tabular}{|c|c|c|c|c|c|c|c|c|c|c|}
\hline \multirow[t]{3}{*}{ Compound } & \multirow[t]{3}{*}{$\mathrm{R}_{1}$} & \multirow[t]{3}{*}{$\mathrm{R}_{2}$} & \multicolumn{8}{|c|}{ Zone of inhibition in $\mathrm{mm}$} \\
\hline & & & \multicolumn{2}{|c|}{ S. aureus } & \multicolumn{2}{|c|}{ E. coli } & \multicolumn{2}{|c|}{ C. albicans } & \multicolumn{2}{|c|}{ A. niger } \\
\hline & & & 50 ug & $100 \mathrm{ug}$ & $\overline{50 \text { ug }}$ & $\overline{100 \mathrm{ug}}$ & 50 ug & $\overline{100 \mathrm{ug}}$ & 50 ug & $100 \mathrm{ug}$ \\
\hline $120 \mathrm{a}$ & $\mathrm{H}$ & $\mathrm{H}$ & 13 & 15 & 10 & 12 & 12 & 15 & 10 & 12 \\
\hline $120 \mathrm{~b}$ & $\mathrm{Cl}$ & $\mathrm{H}$ & 15 & 16 & 15 & 17 & 18 & 20 & 15 & 17 \\
\hline $120 \mathrm{c}$ & $\mathrm{H}$ & $\mathrm{Cl}$ & 15 & 16 & 14 & 15 & 18 & 20 & 13 & 15 \\
\hline $120 d$ & $\mathrm{H}$ & $\mathrm{Br}$ & 11 & 14 & 10 & 12 & 16 & 18 & 11 & 13 \\
\hline $120 \mathrm{e}$ & $\mathrm{H}$ & $\mathrm{OCH}_{3}$ & 12 & 17 & 8 & 10 & 9 & 22 & 20 & 22 \\
\hline $120 f$ & $\mathrm{H}$ & $\mathrm{OH}$ & 15 & 12 & 8 & 11 & 12 & 15 & 11 & 15 \\
\hline $120 \mathrm{~g}$ & $\mathrm{H}$ & $\mathrm{NO}_{2}$ & 15 & 13 & 10 & 11 & 13 & 15 & 10 & 12 \\
\hline $120 \mathrm{~h}$ & $\mathrm{H}$ & $\mathrm{N}\left(\mathrm{CH}_{3}\right)_{2}$ & 12 & 13 & 10 & 12 & 15 & 17 & 9 & 11 \\
\hline
\end{tabular}

owing to the presence of $4-\mathrm{Cl}, 4-\mathrm{OH}$ and $4-\mathrm{NO}_{2}$ in phenyl ring at five-position of pyrazoline ring of prepared derivatives. In some cases, their potencies were equal or more potent as compared to standard drugs (Table 4). Venkataraman and co-workers ${ }^{88}$ designed and developed pyrazoline analogues. All the prepared derivatives were characterized by their anti-inflammatory potency. Some of the evaluated derivatives showed excellent anti-inflammatory potency. The 121 was found to be the most potent. Antibacterial screening results of the compound $\mathbf{1 2 1}$ show that inhibition zones were $8 \mathrm{~mm}, 6 \mathrm{~mm}, 0.0 \mathrm{~mm}$ and 2 $\mathrm{mm}$ for $S$. aureus, B. subtilis, E. coli and P. aeruginosa, respectively. Sridevi et al., ${ }^{89}$ disclosed a library of 1,3,5-trifunctionalized-2-pyrazolines. All the constructed products were screened for their anti-depressant potency. The examined pyrazoline-benzimidazole $\mathbf{1 2 2}$ and pyrazoline-benzoxazole $\mathbf{1 2 3}$ analogues in the library were shown to have important anti-depressant properties in improved forced swimming tests (Table 5).

\subsection{Pyrazole derivatives of anti-microbial potential}

Halogenated derivatives of pyrazole, 1,5-diphenyl-4(phenyl(1H-pyrazol-1-yl)methyl)-1H-pyrazoles
Table 5. Anti-inflammatory activity of phenyl pyrazolo indoloquinoxaline derivatives.

\begin{tabular}{lccc}
\hline Compound & Dose, $\mathrm{mg} / \mathrm{kg}$ & $\begin{array}{l}\text { Mean edema } \\
\text { volume } \pm \text { S.E }\end{array}$ & \% Reduction \\
\hline $\mathbf{1 2 2}$ & 200 & $0.24 \pm 0.145 \mathrm{a}$ & 40.0 \\
$\mathbf{1 2 3}$ & 200 & $0.26 \pm 0.14 \mathrm{a}$ & 35.0 \\
\hline
\end{tabular}

$\mathrm{a}=\mathrm{P}<0.05(\mathrm{Vs})$ control.

were constructed by Menozzi and co-workers. ${ }^{90}$ These compounds were screened for anti-microbial potential. Anti-microbial screening results of the compound 124 show that inhibition zones were $11 \mathrm{~mm}$ and $2 \mathrm{~mm}$ for Bacillus pumilus and Staphylococcus aureus, respectively (Figure 10). All the derivatives demonstrated significant anti-microbial capacity. Ayoob Bazgir and his colleagues ${ }^{91}$ synthesized pyrazolo $\left[4^{\prime}, 3^{\prime}: 5,6\right]$ pyrido [2,3- $d]$ pyrimidine-diones $\mathbf{1 2 5}$. These compound were investigated in vitro for their anti-bacterial and anti-microbial properties (Table 6). Rakesh et al., ${ }^{92}$ synthesized new derivatives of pyrazole $\mathbf{1 2 6}$ by Hantzsch cyclization and modified Bignelli's reaction and all the derivatives exhibited better to moderate activity (Figure 10). 

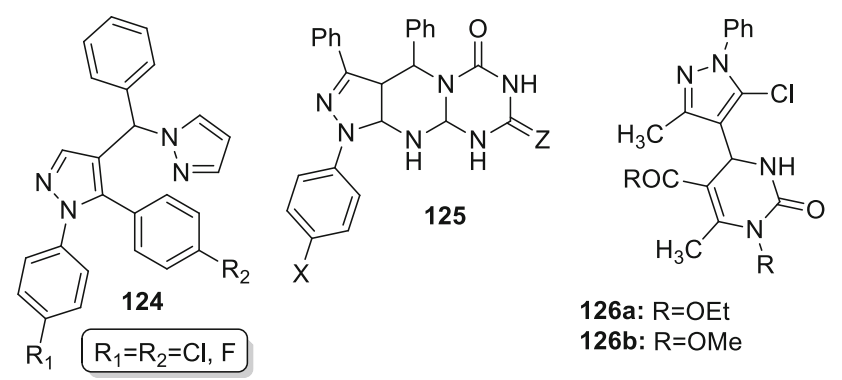

Figure 10. Structures of novel pyrazole derivatives as anti-microbial agents.

\subsection{Analgesic and anti-tubercular capability of pyrazoles}

S. K. Sahu and co-workers ${ }^{93}$ prepared a variety of pyrazole analogues and evaluated them for their analgesic affinity. Compounds $\mathbf{1 2 7}$ and $\mathbf{1 2 8}$ demonstrated highly potent analgesic activity against herpes simplex virus type-1 (HSV-1) and hepatitis-A virus (HAV) (Figure 11). K.K. Sivakumar and co-workers ${ }^{94}$ constructed a library of coumarin-mediated pyrazole analogues. All the compounds were investigated for antiinflammatory and analgesic activities. Compound $\mathbf{1 2 9}$ was observed to have the most powerful analgesic activity. Dias and Salvado ${ }^{95}$ prepared and exposed (4methylthiophen-3-yl)(1H-pyrazol-1-yl)methanone 130, which has an excellent analgesic affinity (Figure 11). A variety of unique 1-(5-(pyridin-3-yl)-1,3,4-thiadiazol2-yl)-1H-pyrazole-4-carbaldehyde derivatives $\mathbf{1 3 1}$ were disclosed by Prathapa et al. Their anti-tubercular and anti-oxidant properties were also scrutinized. All the prepared derivatives revealed significant anti-tubercular affinity. ${ }^{96}$

\subsection{Pyrazoles as anti-viral, anthelmintic and anti-fungal agents}

Osama and co-workers ${ }^{97}$ synthesized 1-(5-(4-(benzyloxy)phenyl)-3-phenyl-4,5-dihydro-1H-pyrazol-1-yl)

ethanone analogues. The analogue having $\mathrm{R}=\mathrm{Cl}$, i.e., 132 displayed powerful anti-viral action against a broad panel of viruses in various cell cultures (HEL Cell cultures) (Table 7). Aymn and co-workers ${ }^{98}$ prepared functionalized pyrazole analogues 133 . These analogues displayed excellent anti-viral potency against Herpes Simplex virus type- 1 and hepatitis A virus using plaque infective assay (Figure 12). El Badwi and co-workers ${ }^{99}$ disclosed that pyrazole-based alkaloids screened from ashwagandha possess significant anthelmintic property. Priyadersini and co-workers ${ }^{100}$ synthesized 2-(5-(4-chlorostyryl)-1-(penta-1,3-dien-2yl)-1H-pyrazol-3-yl)phenol 134 and 2-(5-(4-chlorosty-

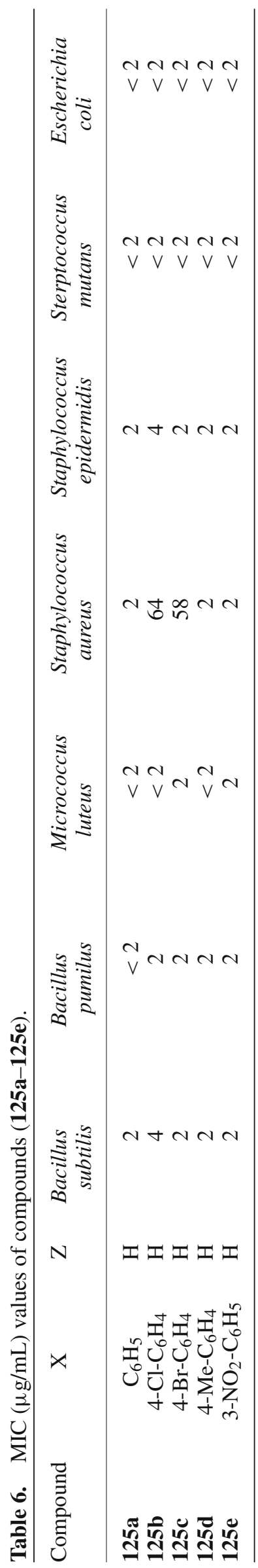


<smiles>O=[N+]([O-])c1ccc(C2CC(Nc3ccc(O)cc3)N=N2)cc1</smiles>

127<smiles>Oc1ccc(NC2=NNC(c3ccccc3O)C2)cc1</smiles>

128<smiles>CC1=NN(C(=O)C2C(=O)OCc3ccccc32)C(=O)/C1=N/Nc1ccccc1</smiles><smiles>Cc1cscc1C(=O)n1cccn1</smiles><smiles>[R]c1nn(-c2nnc(-c3cccnc3)s2)cc1C=O</smiles>

Figure 11. Structures of analgesic and anti-tubercular compounds.

Table 7. Cytotoxicity and antiviral activity of compound 132 in HEL cell cultures, Vero cell cultures and HeLa cell cultures.

\begin{tabular}{|c|c|c|c|c|c|c|}
\hline Compound & $\begin{array}{l}\text { Minimum cytotoxic } \\
\text { concentration }{ }^{\mathrm{a}} \\
(\mathrm{mg} / \mathrm{mL})\end{array}$ & & & $\mathrm{EC}_{50}{ }^{\mathrm{b}}(\mathrm{mg} / \mathrm{mL})$ & & \\
\hline \multirow[t]{2}{*}{$\begin{array}{l}132 \text { in HEL } \\
\text { cell cultures }\end{array}$} & 100 & $\begin{array}{l}\text { Herpes simplex } \\
\text { virus-1 (KOS) }\end{array}$ & $\begin{array}{l}\text { Herpes simplex } \\
\text { virus-2 }(G)\end{array}$ & Vaccinia virus & $\begin{array}{l}\text { Vesicular } \\
\text { stomatitis } \\
\text { virus }\end{array}$ & $\begin{array}{l}\text { Herpes simplex } \\
\text { virus-1 TK KOS } \\
\text { ACV }^{\mathrm{r}}\end{array}$ \\
\hline & & $>20$ & $>20$ & $7 \pm 3$ & $>20$ & $>20$ \\
\hline \multirow[t]{2}{*}{$\begin{array}{l}132 \text { in Vero } \\
\text { cell cultures }\end{array}$} & 20 & $\begin{array}{l}\text { Parainfluenza- } \\
3 \\
\text { virus }\end{array}$ & Reovirus-1 & Sindbis virus & $\begin{array}{c}\text { Coxsackie } \\
\text { virus B4 }\end{array}$ & $\begin{array}{l}\text { Punta toro } \\
\text { virus }\end{array}$ \\
\hline & & $>4$ & $>4$ & $>4$ & $>4$ & $>4$ \\
\hline \multirow[t]{2}{*}{$\begin{array}{l}132 \text { in HeLa } \\
\text { cell cultures }\end{array}$} & $>20$ & $\begin{array}{l}\text { Vesicular } \\
\text { stomatitis } \\
\text { virus }\end{array}$ & $\begin{array}{c}\text { Coxsackie } \\
\text { virus B4 }\end{array}$ & $\begin{array}{l}\text { Respiratory } \\
\text { syncytial virus }\end{array}$ & & \\
\hline & & $>20$ & $>20$ & $>20$ & & \\
\hline
\end{tabular}

${ }^{a}$ Required to cause a microscopically detectable alteration of normal cell morphology. ${ }^{b}$ Required to reduce virus-induced cytopathogenicity by $50 \%$.

ryl)-1H-pyrazol-3-yl)phenol 135 and observed them possessing moderate potency against black mold. Hassan ${ }^{101}$ observed that compound $\mathbf{1 3 5}$ enclosed excellent efficacy against $C$. albicans (Figure 12).

\subsection{Usefulness of pyrazole-based hypotensive and insecticidal agents}

Kevser Erol and co-workers ${ }^{102}$ constructed some analogues of 2-(2-(3,5-diphenyl-4,5-dihydro-1H-pyrazol1-yl)thiazol-4-yl)-5-methoxyphenol (137a and 137b) and evaluated their hypotensive capability by a tailcuff approach using catapres as the reference standard (Figure 13). All the inspected analogues illustrated considerable hypotensive capacities (Table 8). Silver and Soderlund ${ }^{103}$ prepared pyrazole-based insecticides (138 and 139) and studied the mechanism of action of prepared entities mediated on available toxicological, pharmacological and electrophysiological information and observed these entities to act at neuronal target sites (Figure 13).

\subsection{Anti-nociceptive capacity of pyrazole derivatives}

Carlos F. Mello and co-workers ${ }^{104}$ examined the participation of spinal noradrenergic and serotonergic systems in anti-nociception prompted by potent pyrazolines PPCA 140 and MPCA 141 (Figure 14). The results revealed that spinal $\alpha 2$-adrenoreceptors and 5-HT receptors are involved and prompted by PPCA 140 and MPCA 141, but not elicited by dipyrone.

\subsection{MAO and ACE-inhibiting activity of pyrazoles}

B. Bizzarri and co-workers ${ }^{105}$ prepared a library of 1-(but-1-en-2-yl)-5-(4-chlorophenyl)-3-phenyl-4,5dihydro-1H-pyrazole analogues 142 and examined them as inhibitors of monoamine oxidase $\mathrm{B}$ (MAO-B) and monoamine oxidase A (MAO-A) isoforms (Figure 15). The synthesized compounds displayed inhibiting action with micromolar $(\mu \mathrm{M})$ values against MAO-selectivity and observed to be beneficial as coadjuvants in the medication of Alzheimer's disease and Parkinson's 
<smiles>CC(=O)N1N=C(c2ccc(Cl)cc2)CC1c1ccc2ccccc2c1-c1cccc2sc3c(-c4ccc(N)cc4Cl)ncnc3c12</smiles>

132<smiles>C=C(/C=C\C)n1nc(-c2ccccc2O)cc1/C=C/c1ccc(Cl)cc1</smiles><smiles>CC1(C)CC(=O)c2cc(-c3c(Br)c(-c4ccc(Br)cc4)nn3-c3ccc(S(N)(=O)=O)cc3)[nH]c2C1</smiles>

Figure 12. Some potent anti-viral, anthelmintic and anti-fungal agents.

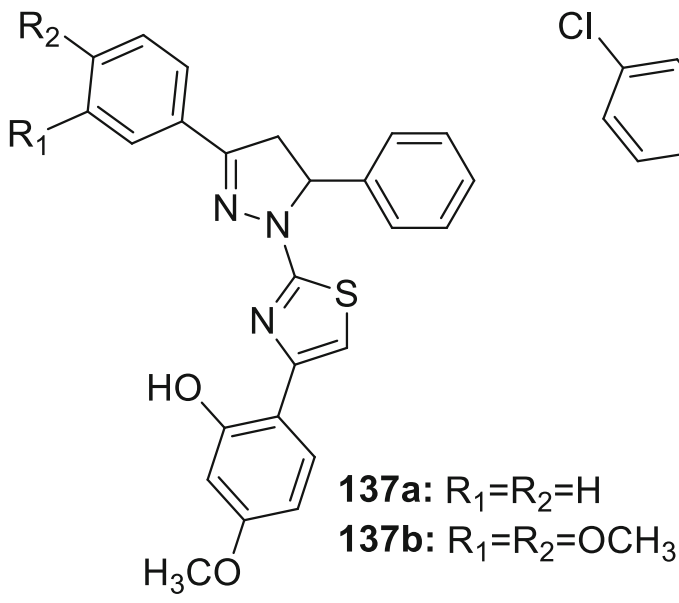<smiles>COc1ccc(NC(=O)N2CC(c3ccccc3)C(c3ccc(Cl)cc3)=N2)cc1</smiles><smiles>CC(=O)C1(C)CN(C(=O)Nc2ccc(Cl)cc2)N=C1c1ccc(Cl)cc1</smiles>

Figure 13. Structures of pyrazole-based hypotensive and insecticidal agents.

Table 8. Hypotensive activity of compounds (137a and 137b).

Compound 137a 137b
Reduction of arterial blood pressure $(\mathrm{mm} \mathrm{Hg})(\mathrm{X} \pm \mathrm{SEM})$

$13.80 \pm 3.45$

$12.29 \pm 3.41$ disease (PD) (Table 9). U. Salgin-Goksen and co-workers ${ }^{106}$ constructed a variety of pyrazole derivatives and these derivatives were observed to be inhibitors of human MAO-selectivity. M. Bonesi and co-workers disclosed a series of pyrazoles $\mathbf{1 4 3}$ and examined them as an angiotensin-I-converting enzyme (ACE)inhibitory agents by carrying out different assays (Figure 15). ${ }^{107}$ These analogues of pyrazole presented efficient ACE-inhibitory potency with an $\mathrm{IC}_{50}$ value of $0.123 \mathrm{mM}$. A new molecular series of COX-2 inhibitors have been recently disclosed by Qi-Huang Zheng and co-workers. The products were tested for their inhibitory property. The investigation revealed that $\mathbf{1 4 4 a}$ and

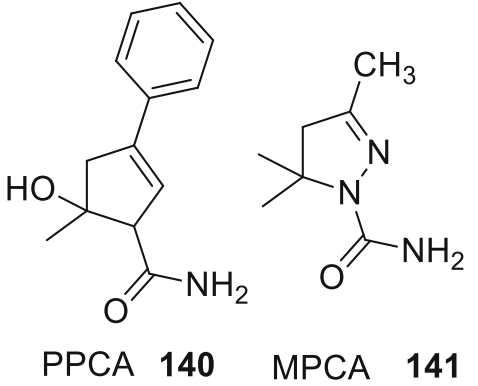

Figure 14. Structures of unique pyrazolines, MPCA and PPCA.

144b demonstrate powerful inhibitory efficiency in the MDA-MB-435 human cancer cell line as compared to stranded entity celecoxib. ${ }^{108}$

\subsection{Anti-mycobacterial, anti-helmintic and} anti-HIV activity of pyrazoles

Mamolo and co-workers ${ }^{109}$ synthesized pyridine-based pyrazole analogues and screened them for their in vitro 

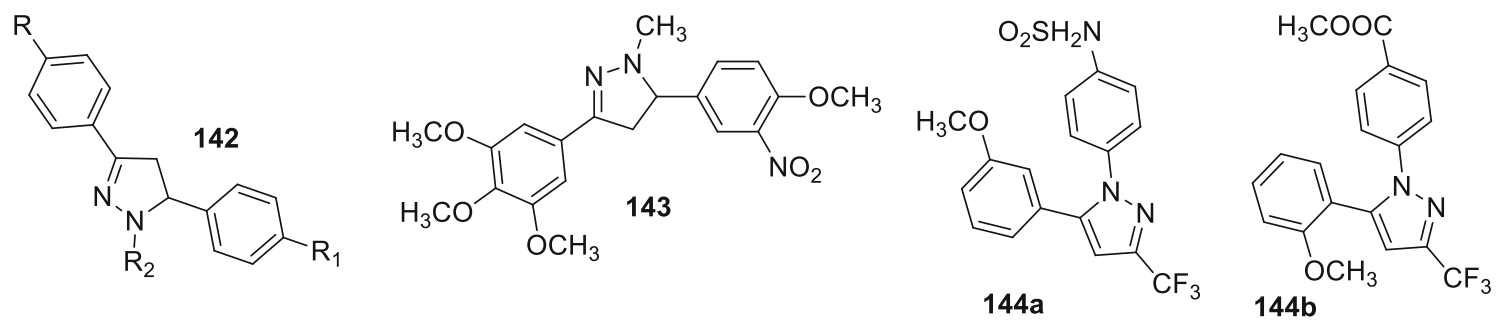

Figure 15. Structures of MAO and ACE inhibitors of pyrazole.

Table 9. Minimal inhibitory concentration (MIC) of compounds 142 and metronidazole (M) against H. pylori strains.

\begin{tabular}{llllcrr}
\hline Compound & $\mathrm{R}$ & $\mathrm{R}_{1}$ & $\mathrm{R}_{2}$ & \multicolumn{3}{c}{$\mathrm{MIC}(\mu \mathrm{g} / \mathrm{mL})$} \\
\cline { 5 - 6 } & & & & Range & $\mathrm{MIC}_{50}$ & $\mathrm{MIC}_{90}$ \\
\hline $\mathbf{1 4 2 a}$ & $\mathrm{H}$ & $-\mathrm{C}(\mathrm{O}) \mathrm{CH}_{3}$ & $4-\mathrm{Cl}$ & $2-8$ & 4 & 8 \\
$\mathbf{1 4 2 b}$ & $2-\mathrm{OH}$ & $-\mathrm{C}(\mathrm{O}) \mathrm{CH}_{3}$ & $4-\mathrm{Cl}$ & $2-8$ & 4 & 8 \\
$\mathbf{1 4 2 c}$ & $2-\mathrm{OH}$ & $-\mathrm{C}(\mathrm{O}) \mathrm{CH}_{3}$ & $3,4-\mathrm{OCH}_{3}$ & $2-16$ & 8 & 16 \\
$\mathbf{1 4 2 d}$ & $4-\mathrm{OH}$ & $-\mathrm{C}(\mathrm{O}) \mathrm{CH}_{3}$ & $2-\mathrm{Cl}$ & $1-8$ & 2 & 8 \\
$\mathbf{1 4 2}$ & $4-\mathrm{OH}$ & $-\mathrm{C}(\mathrm{O}) \mathrm{CH}_{3}$ & $4-\mathrm{Cl}$ & $0.25-16$ & 8 & 16 \\
$\mathbf{1 4 2 f}$ & $4-\mathrm{OH}$ & $-\mathrm{C}(\mathrm{O}) \mathrm{CH}_{3}$ & $2-\mathrm{OCH}_{3}$ & $4-32$ & 8 & 8 \\
$\mathbf{1 4 2 g}$ & $4-\mathrm{OH}$ & $-\mathrm{C}(\mathrm{O}) \mathrm{CH}_{3}$ & $4-\mathrm{OCH}_{3}$ & $2-16$ & 4 & 8 \\
\hline
\end{tabular}
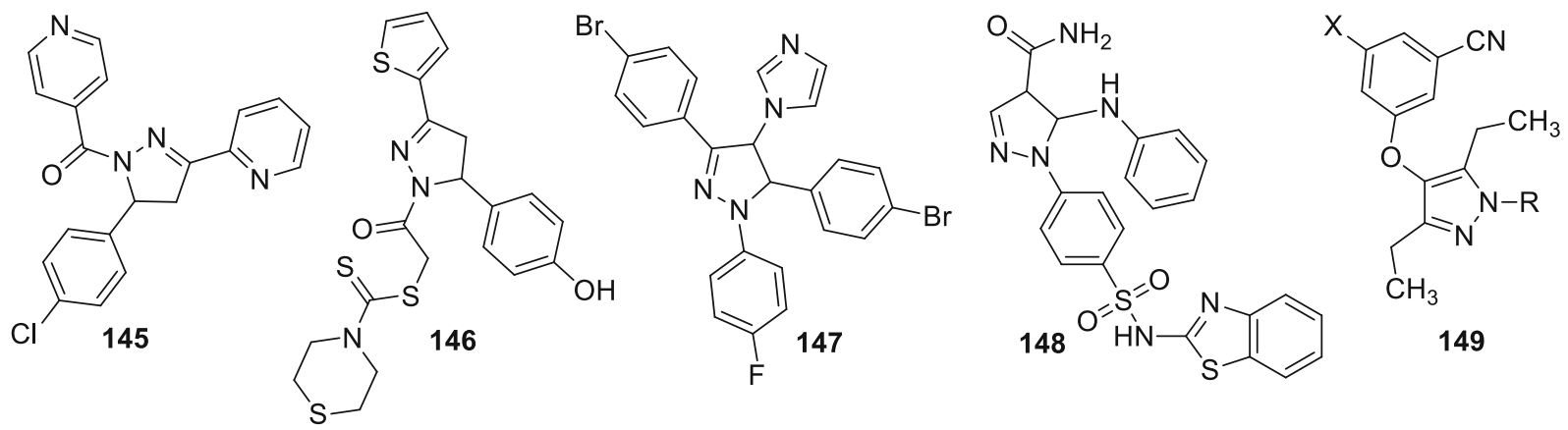

Figure 16. Structures of novel anti-mycobacterial, anti-helmintic and anti-HIV agents.

anti-mycobacterial potency. Compound 145 confirmed potent anti-mycobacterial capacity. Ozdemir and coworkers ${ }^{110}$ reported novel thiophene-based pyrazole analogues and tested them for in vitro anti-mycobacterial capacity against Mycobacterium tuberculosis H37Rv (Figure 16). The activity of the $\mathbf{1 4 5}$ against $M$. tuberculosis $\mathrm{H}_{37} \mathrm{Rv}$ and M. tuberculosis $\mathrm{H} 4$ clinical isolate was observed to be 8 and 8, respectively. Compound 146 possessed the potent anti-mycobacterial capacity. M. G. Mamolo and co-workers ${ }^{111}$ disclosed several imidazolebased pyrazole analogues and screened them for their in vitro anti-mycobacterial and anti-fungal potencies. The pyrazole analogue 147 exhibited a remarkable antitubercular affinity against Mycobacterium tuberculosis strain $H 37 R v$ and an outstanding anti-fungal capacity against the clinical strain of Candida albicans. ${ }^{112}$ Sreenivara and co-workers ${ }^{113}$ prepared a library of pyrazole derivatives 148 and estimated their anti-helminitic efficacy against earthworms. All the derivatives demonstrated significant to modest antihelminitic capacity (Figure 16). Charles and coworkers ${ }^{114-116}$ constructed 3-cyanophenoxypyrazoles 149 and investigated it in vitro against HIV. The compounds illustrated excellent anti-HIV affinity (Table 10).

\subsection{Role of pyrazoles as anti-tumor and anti-oxidant}

A variety of 5-(1H-indol-3-yl)-3-phenyl-4,5-dihydro1H-pyrazole-1-carbothioamide derivatives $\mathbf{1 5 0}$ were prepared by Nassar and his colleagues and the derivatives were also screened against tumors ${ }^{117}$ and microbes (Figure 17). ${ }^{118}$ Activity of the 150 against a human breast carcinoma cell line (MCF7) and a liver carcinoma cell line (HEPG2) was observed to be 2.62 and 2.48 , 
<smiles>NC(=S)N1N=C(c2ccccc2)CC1c1c[nH]c2ccccc12</smiles><smiles>CC1(C(F)(F)F)CC=NN1C(N)=O</smiles>

151

Figure 17. Structures of potent anti-tumor and anti-oxidant compounds.

respectively. C.F. Mello and co-workers ${ }^{119}$ prepared a library of pyrazoles 151 and tested them for anti-oxidant activity. All pyrazoles displayed reasonable potency.

\subsection{Pyrazole-mediated anti-convulsants and anti-depressants}

Adriana Bolasco and co-workers synthesized a new variety of pyrazole analogues and examined their selectively inhibiting capability against monoamine (MAO) oxidase A and B. The synthesized compounds 152a and 152b were shown to be more potent (Figure 18), reversible and selective inhibitors of MAO-A as compared to MAO-B (Table 11). ${ }^{120}$ Abdel-Aziz and coworkers disclosed a novel variety of pyrazole analogues (153a, 153b and 153c). ${ }^{121}$ These compounds showed anti-depressant potency using tail suspension behavioral despair test and anti-convulsant potency against pentylenetetrazol (PTZ)-induced seizures in mice (Figure 18). Analogues 153a, 153b and 153c showed a protective effect against tonic-clonic seizure induced by intraperitoneal (I.P) injection of PTZ at a dose amount of $20 \mathrm{mg} / \mathrm{kg}$ (Table 12). ${ }^{122}$

\subsection{Angiogenic and nematocidal activities of functionalized pyrazoles}

Kumar et al., synthesized functionalized pyrazoles 54 and screened them for their antiangiogenic activity by the chorioallantoic membrane (CAM) assay (Figure 19). ${ }^{123}$ Investigation reveals that functionalized pyrazoles 54 exhibit excellent cytotoxic and angiogenic properties (Table 13). Cheng et al., developed novel pyrazole carboxamides and investigated their nematocidal activity. ${ }^{124}$ The preliminary insecticidal activity showed that some of them possessed good insecticidal activities against Meloidogyne incognita. Avermectin was used as control. The nematocidal activity decreased when the methyl group was replaced by ethyl group on the $N$-position of the amide group (Table 14). Likewise, Fei et al., synthesized a series of novel thioether bridged 
<smiles>COc1ccccc1C1CC(c2ccc(O)cc2)=NN1C(C)=O</smiles><smiles>COc1ccccc1C1CC(c2ccc(O)cc2O)=NN1C(C)=O</smiles><smiles>CCOC(=O)c1[nH]n(C(=O)c2ccccc2)c(=O)c1C#N</smiles><smiles>CCOC(=O)c1[nH]n(C(=O)C2=Nc3ccccc3C2)c(=O)c1C#N</smiles>

Figure 18. Structures of pyrazole-mediated anti-convulsants and anti-depressants.

Table 11. Monoamine oxidase inhibitory activity of compound (152a and 153b).

\begin{tabular}{lcccc}
\hline Compound & MAO IC & MAO-A IC & & MAO-B IC \\
50 & SI selectivity $^{\mathrm{a}}$ \\
\hline 152a & $3.0 \times 10^{-5} \pm 0.05$ & $8.8 \times 10^{-9} \pm 0.01$ & $1.0 \times 10^{-4} \pm 0.06$ & 11363 \\
152b & $4.0 \times 10^{-5} \pm 0.02$ & $8.0 \times 10^{-9} \pm 0.01$ & $1.3 \times 10^{-4} \pm 0.03$ & 16250 \\
\hline
\end{tabular}

${ }^{a}$ SI: selectivity index $=\mathrm{IC}_{50}(\mathrm{MAO}-\mathrm{B}) / \mathrm{IC}_{50}(\mathrm{MAO}-\mathrm{A})$.

Table 12. Antidepressant activities of the compounds 153a-153c as compared to imipramine.

\begin{tabular}{lcc}
\hline Compound $^{\text {a }}$ & $\begin{array}{l}\text { Duration of immobility } \\
\text { (s) (mean } \pm \text { S.E.M. })\end{array}$ & $\begin{array}{l}\text { Change from } \\
\text { control (\%) }\end{array}$ \\
\hline 153a & $183.90 \pm 9.30$ & -24.41 \\
153b & $198.70 \pm 6.80$ & -18.33 \\
153c & $153.30 \pm 4.60$ & -36.99 \\
Imipramine & $132.00 \pm 2.60$ & -45.75 \\
\hline
\end{tabular}

Values represent the mean \pm S.E.M. $(\mathrm{n}=6)$; ${ }^{\mathrm{a}}$ Compounds and imipramine were tested at $10 \mathrm{mg} / \mathrm{kg}$ dose level, ip.
$\mathrm{N}$-phenylpyrazole derivatives and insecticidal activities (Figure 19). ${ }^{125}$ 56a, 56b and 56c with sulfur-containing heterocycle substituents possessing good insecticidal activity against Musca domestica $L$. among the series $\left(\mathrm{LC}_{50}=0.67-1.30 \mu \mathrm{g} / \mathrm{g}\right)$.

\subsection{Anti-metastatic activities of hybrids based on coumarin/pyrazole oximes}

A series of hybrids based on coumarin/pyrazole oxime have been synthesized by Dai et al. The formed compounds were screened for their metastatic activities (Figure 20). ${ }^{126}$ Metastatic activities reveal that $\mathbf{1 5 7}$ 154a: $\mathrm{R}=\mathrm{H}, \mathrm{R}_{1}=\mathrm{H}, \mathrm{R}_{2}=\mathrm{H}, \mathrm{R}_{3}=\mathrm{H}, \mathrm{R}_{4}=\mathrm{H}, \mathrm{R}_{5}=\mathrm{H}$

154b: R=H; $\mathrm{R}_{1}=\mathrm{H}, \mathrm{R}_{2}=\mathrm{F}, \mathrm{R}_{3}=\mathrm{H}, \mathrm{R}_{4}=\mathrm{H}, \mathrm{R}_{5}=\mathrm{H}$

154c: $\mathrm{R}=\mathrm{H}, \mathrm{R}_{1}=\mathrm{H}, \mathrm{R}_{2}=\mathrm{H}, \mathrm{R}_{3}=\mathrm{H}, \mathrm{R}_{4}=\mathrm{Cl}, \mathrm{R}_{5}=\mathrm{H}$

154d: R=H, $\mathrm{R}_{1}=\mathrm{H}, \mathrm{R}_{2}=\mathrm{CH}_{3}, \mathrm{R}_{3}=\mathrm{H}, \mathrm{R}_{4}=\mathrm{H}, \mathrm{R}_{5}=\mathrm{H}$

154e: $\mathrm{R}=\mathrm{H}, \mathrm{R}_{1}=\mathrm{H}, \mathrm{R}_{2}=\mathrm{CH}_{3}, \mathrm{R}_{3}=\mathrm{H}, \mathrm{R}_{4}=\mathrm{Cl}, \mathrm{R}_{5}=\mathrm{H}$

154f: $\mathrm{R}=\mathrm{H}, \mathrm{R}_{1}=\mathrm{H}, \mathrm{R}_{2}=\mathrm{Cl}, \mathrm{R}_{3}=\mathrm{H}, \mathrm{R}_{4}=\mathrm{CH}_{3}, \mathrm{R}_{5}=\mathrm{H}$<smiles>[R2]c1ccc(-c2c(C(=O)OCC)c(C)nn2-c2ccc([R])c([R])c2[R])c([R])c1[R]</smiles><smiles>[R]SCSC1=C(N)C(c2c(Cl)cc(C(F)(F)F)cc2Cl)C=C1C#N</smiles>

156a: $R_{8}=$<smiles>[R6][R]1cccc(C([R])C(=O)c2cn(C)nc2C)c1</smiles><smiles>Cc1nnc(C#[R6][AsH2])s1</smiles>

156c: $R_{8}=\left[\begin{array}{ll|}N \\ N\end{array}\right.$

Figure 19. Structure of pyrazole carboxamides. 
Table 13. $\mathrm{IC}_{50}$ values of compounds $\mathbf{5 4 a - 5 4 g}$ on trypan blue and MTT assay at $48 \mathrm{~h}$ in MCF-7 cells.

\begin{tabular}{lcc}
\hline Compound & $\begin{array}{c}\text { Trypan blue assay } \\
\text { IC } 50 \text { value }(\mu \mathrm{M})\end{array}$ & $\begin{array}{l}\text { MTT assay } \\
\text { IC } 50 \text { value }(\mu \mathrm{M})\end{array}$ \\
\hline $\mathbf{5 4 a}$ & $19 \pm 0.27$ & $21 \pm 0.18$ \\
$\mathbf{5 4 b}$ & $7.9 \pm 0.07$ & $7.6 \pm 0.08$ \\
$\mathbf{5 4 c}$ & $17 \pm 0.17$ & $16 \pm 0.22$ \\
$\mathbf{5 4 e}$ & $44 \pm 0.12$ & $49 \pm 0.16$ \\
$\mathbf{5 4 f}$ & $71 \pm 0.19$ & $65 \pm 0.13$ \\
$\mathbf{5 4 g}$ & $10.6 \pm 0.07$ & $10.4 \pm 0.08$ \\
\hline
\end{tabular}

Table 14. Control efficacy of compounds 55 against Meloidogyne incognita at $40 \mathrm{mg} / \mathrm{L}$.

\begin{tabular}{lllc}
\hline Compound & $\mathrm{R}_{6}$ & $\mathrm{R}_{7}$ & Inhibitory (\%) \\
\hline $\mathbf{5 5 a}$ & $\mathrm{CH}_{3}$ & $2,4-\mathrm{F}_{2}$ & 80 \\
$\mathbf{5 5 b}$ & $\mathrm{Et}$ & $4-\mathrm{Cl}$ & 64 \\
$\mathbf{5 5 c}$ & $\mathrm{CH}_{3}$ & $4-\mathrm{Cl}$ & 80 \\
$\mathbf{5 5 d}$ & $\mathrm{CH}_{3}$ & $3,4-\mathrm{Cl}_{2}$ & 94.5 \\
$\mathbf{5 5 e}$ & $\mathrm{CH}_{3}$ & $4-\mathrm{Br}$ & 90 \\
$\mathbf{5 5 f}$ & $\mathrm{CH}_{3}$ & $4-\mathrm{CH}_{3}$ & 91.8 \\
$\mathbf{5 5 g}$ & $\mathrm{CH}_{3}$ & $4-\mathrm{COOMe}^{2}$ & 80 \\
$\mathbf{5 5 h}$ & $\mathrm{CH}_{3}$ & $4-\mathrm{OCF}_{3}$ & 90.9 \\
$\mathbf{5 5 i}$ & $\mathrm{CH}_{3}$ & $3-\mathrm{CF}_{3}$ & 60 \\
Avermectin & & & 100 \\
\hline
\end{tabular}

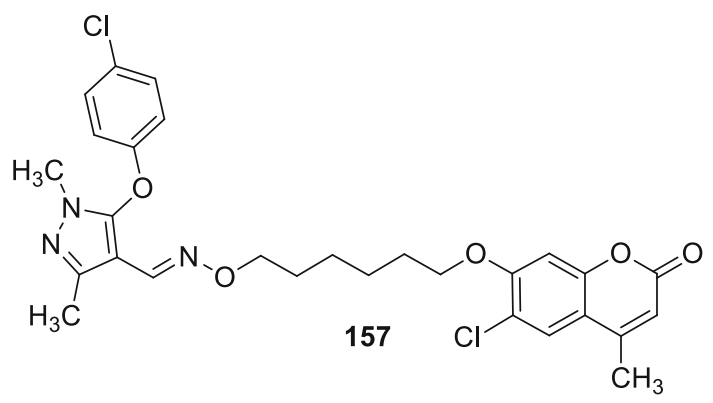

Figure 20. Structure of hybrids based on coumarin/pyrazole oxime.

displays significant anti-metastasis effects through inhibiting cell migration and invasion in highly metastatic SMMC-7721 cell line, and dose-dependently reverses TGF- $\beta 1$-induced epithelial-mesenchymal transition (EMT) procedure

\section{Conclusions}

Numerous biological activities of pyrazoles and various synthetic protocols to construct pyrazoles have been highlighted in this review article. In the recent past, a lot of research has been carried out for the development of pyrazole scaffolds. In the case of green approaches, $\mathrm{BMIMBF}_{4}$ IL, zirconium dioxide NPs, organo-nanocatalyst, ultrasonic irradiation, copper(II) IL and [bmim] OH IL are the most novel approaches; while, in the case of classical approaches, synthesis of pyrazoles from methylene ketones, alkanyl bromides and propargylic alcohols are some novel approaches. However, currently, there are some important challenges that need to be dealt with in order to further develop the chemistry of pyrazoles. These challenges deal with proficiency for quantitative chemical yields in the formation of pyrazoles, precisely characterizing the inhibiting affinity of the pyrazoles and generating novel pyrazoles with a biological profile in the submicromolar range. It is expected that this review will be helpful in future research and for new and novel ideas in the quest of rational designs for syntheses of more promising pyrazoles.

\section{Future prospective}

The aim of this review is to summarize recent synthetic developments and biological activities of pyrazole derivatives. This review will inspire the scientists to plan and construct a new and potent series of bioactive pyrazole derivatives using highly efficient synthetic protocols. Further, the review will be cooperative to achieve structural-modifications intended to understand and enhance the inhibitory efficiency of pyrazoles. For future research, authors have listed a number of recommendations. Following are these recommendations: (i) it is suggested to couple other molecular frameworks, such as isatin, carbazole, benzothiophene, thiophene and terpyridine derivatives, with pyrazoles in order to enhance the bioactivity of pyrazole-based drugs; (ii) to replace current commercial bioactive drugs or to construct commercial-level pyrazoles-based drugs; it is important to produce drugs that contain inexpensive and commercially available starting chemicals, milder reaction conditions and one-pot synthetic approach. Further, construction must include properties of quantitative yield and eco-friendly procedures, i.e., MWassisted approaches and IL-mediated methods; (iii) in order to further enhance the yield of pyrazoles, it is recommended to investigate nano-catalytic systems and sono-mediated approaches; (iv) nowadays, cytotoxicity is the main issue of drugs; therefore, the researcher should focus on cytotoxic properties of pyrazoles. Further, solubility of pyrazoles is also required to be improved; (iv) dimer, trimer, tetramer and star-type polymeric pyrazoles should also be synthesized and investigated for anti-cancer activity; (v) to design and 
develop extremely bio-operative pyrazole derivatives for the selective and sensitive inhibiting the target cells it is important to understand the structure-activity relationship and develop computational models; and (vi) in order to make pyrazoles highly soluble in $\mathrm{H}_{2} \mathrm{O}$, pyrazoles must be containing in the association of a hydrophobic region. It is hoped that this review will assist to increase knowledge and will be supportive of new thoughts in scheming more operative synthetic protocols for pyrazoles and in developing more potent drugs.

\section{References}

1. Eftekhari-Sis B, Zirak M and Akbari A 2013 Arylglyoxals in Synthesis of Heterocyclic Compounds Chem. Rev. 1132958

2. Ansari A, Ali A and Asif M 2017 Biologically active pyrazole derivatives New New J. Chem. 4116

3. Ju Y and Varma R S 2006 Aqueous N-Heterocyclization of Primary Amines and Hydrazines with Dihalides: Microwave-Assisted Syntheses of N-Azacycloalkanes, Isoindole, Pyrazole, Pyrazolidine, and Phthalazine Derivatives J. Org. Chem. 71135

4. Zárate-Zárate D, Aguilar R, Hernández-Benitez R I, Labarrios E M, Delgado F and Tamariz J 2015 Synthesis of $\alpha$-ketols by functionalization of captodative alkenes and divergent preparation of heterocycles and natural products Tetrahedron 716961

5. Gordon E M, Barrett R W, Dower W J, Fodor S P A and Gordon M A 1994 Gallop Applications of Combinatorial Technologies to Drug Discovery. 1. Background and Peptide Combinatorial Libraries J. Med. Chem. 37 1385

6. Ardiansah B 2017 Recent reports on pyrazole-based bioactive compounds as candidate for anticancer agents Asian J. Pharm. Clin. Res. 1245

7. Srivastava M, Singh J, Singh S B, Tiwari K, Pathak K V and Singh J 2012 Synthesis of novel fused heterocycleoxa-aza-phenanthrene and anthracene derivatives via sequential one-pot synthesis in aqueous micellar system Green Chem. 14901

8. Pai G and Chattopadhyay A P 2016 N-arylation of nitrogen containing heterocycles with aryl halides using copper nanoparticle catalytic system Tetrahedron Lett. 573140

9. Bekhit A A, Hassan A M, Abd El Razik H A, El-Miligy M M, El-Agroudy E J and Bekhit Ael-D 2015 New heterocyclic hybrids of pyrazole and its bioisosteres: Design, synthesis and biological evaluation as dual acting antimalarial-antileishmanial agents Eur. J. Med. Chem. 9430

10. Sony J K and Ganguly S 2016 A battle against AIDS: New pyrazole key to an older lock-reverse transcriptase Int. J. Pham Pharm. Sci. 875

11. Surendra Kumar R, Arif I A, Ahamed A and Idhayadhulla A 2016 Antiinflammatory and antimicrobial activities of novel pyrazole analogues Saudi J. Biol. Sci. 23614

12. Alam R, Wahi D, Singh R, Sinha D, Tandon V, Grover A and Rahisuddin 2016 Design, synthesis, cytotoxicity, $\mathrm{Hu}$ Topoll $\alpha$ inhibitory activity and molecular docking studies of pyrazole derivatives as anticancer agents Bioorg. Chem. 6977

13. Shamsuzzaman S, Siddiqui T, Alam M G and Dar A M 2015 Synthesis, characterization and anticancer studies of new steroidal oxadiazole, pyrrole and pyrazole derivatives J. Saudi Chem. Soc. 19387

14. Faisal M, Hussain S, Haider A, Saeed A and Larik F A 2018 Assessing the effectiveness of oxidative approaches for the synthesis of aldehydes and ketones from oxidation of iodomethyl group Chem. Pap. 73 1053

15. Kees K L, Fitzgerald J J, Steiner K E, Mattes, Mihan B, Tosi T, Mondoro D and McCaleb M L 1996 New potent antihyperglycemic agents in $\mathrm{db} / \mathrm{db}$ mice: synthesis and structure-activity relationship studies of (4-substituted benzyl) (trifluoromethyl)pyrazoles and -pyrazolones $J$. Med. Chem. 393920

16. Bailey D M, Hansen P E, Hlavac A G, Baizman E R, Pearl J, Defelice A F and Feigenson M E 1985 3,4Diphenyl-1H-pyrazole-1-propanamine antidepressants J. Med. Chem. 28256

17. Michon V, Penhoat C H D, Tombret F, Gillardin J M, Lepage F and Berthon L 1995 Preparation, structural analysis and anticonvulsant activity of 3- and 5-aminopyrazole $N$-benzoyl derivatives Eur. J. Med. Chem. 30147

18. Wiley R H and Wiley P 1964 Pyrazolones, Pyrazolidones and Derivatives (New York: Wiley) p. 102

19. Jamwal A, Javed A and Bhardwaj V 2013 A review on pyrazole derivatives of pharmacological potential $J$. Pharm. BioSci. 3114

20. Haufel J, Breitmaier E 1974 Synthesis of Pyrazolo Heteroaromatic Compounds by Means of 5-Amino3-methyl-1-phenylpyrazole-4-carbaldehyde Angew. Chem. 13604

21. Heller S T and Natarajan S R 2006 1,3-Diketones from Acid Chlorides and Ketones: A Rapid and General OnePot Synthesis of Pyrazoles Org. Lett. 82675

22. Faisal M, Saeed A, Larik F A, Ghumro S A, Rasheed S and Channar P A 2018 WOWS Sol-Gel Based Synthesis and Structural, Morphological, Electrical and Magnetic Characterization of Co-Sm Doped M-Type Barium Hexaferrite Materials J. Electron. Mater. 47 7011

23. Wyde P R, Gilbert B E and Ambrose M W 1989 Comparison of the anti-respiratory syncytial virus activity and toxicity of papaverine hydrochloride and pyrazofurin in vitro and in vivo Antiviral Res. 11 15

24. Bakr F A W and Kamal M D 2012 Synthesis and applications of bipyrazole systems ARKIVOC 1491

25. Xia M, Zhang T, Wang Y and Xing G 2006 "Tetrahydroindole derivatives and tetrahydroindazole derivatives, and use thereof" WO 2006133634

26. Rosati O, Curini M, Marcotullio M C, Macchiarulo A, Perfumi M, Mattioli L, Rismondo F and Cravotto G 2007 Synthesis, docking studies and anti-inflammatory 
activity of 4,5,6,7-tetrahydro-2H-indazole derivatives Bioorg. Med. Chem. 153463

27. Nakhai A 2009 In Synthetic studies of Nitrogen containing heterocycles, particularly pyrazole and benzotriazine derivatives (Biovetenskaper och näringslära/Biosciences and Nutrition) (Stockholm: Karolinska Institutet) p. 111

28. Ansari A, Ali A and Asif M 2017 biologically active pyrazole derivatives New J. Chem. 4116

29. Md J A, Ozair A, Perwaiz A and Mohammad J N 2015 A Review on Pyrazole chemical entity and Biological Activity International J. Pharm. Sci. Res. 61433

30. Dewangan D, Kumar T, Alexander A, Nagori K and Tripathi D K 2003 Pyrazole: Their Chemistry and Pharmacological Potentials: A Review Curr. Pharmac. Res. Sat. 4369

31. Arunachalam S, Gowrishankar N L, Krishnan A, Prakash M, Muhsin T, Naseena U and Poornima G 2018 A brief review on pyrazole derivatives possesing variouspharmacological and biological evaluation World J. Pharm. Pharma. Sci. 51496

32. Raj K B 2007 Heterocyclic Chemistry $4^{\text {th }}$ edn. (New International Publishers)

33. Krygowski T M, Anulewicz R, Cyrafiski M K, Puchala A, Rasata D 1998 Separation of the energetic and geometric contribution to the aromaticity. Part IX. Aromaticity of pyrazoles in dependence on the kind of substitution Tetrahedron $\mathbf{5 4} 12295$

34. Behr L C, Fusco R and Jarboe C H 1967 The Chemistry of Heterocyclic Chemistry: Pyrazoles, Pyrazolines, Pyrazolidines, Indazoles and Condensed Rings (Wiley \& Sons: London) p. 113

35. Ragab E A, Metwally N H and Mohamed M S 2017 Synthesis of some novel pyrazolo [1,5-a] quinazolines and their fused derivatives Synth. Commun. 2148

36. Arunachalam S, Gowrishankar N L, Krishnan A, Prakash M, Muhsin T, Naseena U and Poornima G 2018 A brief review on pyrazole derivatives possessing various pharmacological and biological evaluation World J. Pharm. Pharma. Sci. 51496

37. Ciccolini C, Mari M, Lucarini S, Mantellini F, Piersanti G and Favi G 2018 Polycyclic Indolines by an Acid-Mediated Intramolecular Dearomative Strategy: Reversing Indole Reactivity in the Pictet-SpenglerType Reaction Adv. Synth. Cat. 3604060

38. Desalegn N 2005 Kinetic Studies of The Thermolysis of 3-Halogenated-4, 5-Dihydro-3h-Pyrazoles (Georgia State University: Atlanta, Georgia) p. 84

39. Corradi A, Leonelli C, Rizzuti A, Rosa R, Veronesi P, Grandi R, Baldassari S and Villa C 2007 New "green" approaches to the synthesis of pyrazole derivatives Molecules 71482

40. Beyzaei H, Motraghi Z, Aryan R, Zahedi M M and Samzadeh-Kermani A 2017 Green One-pot Synthesis of Novel Polysubstituted Pyrazole Derivatives as Potential Antimicrobial Agents Acta Chim. Slov. 644911

41. Motamedi A, Sattari E, Mirzaei P, Armaghan M and Bazgir A 2014 An efficient and green synthesis of phthalide-fused pyrazole and pyrimidine derivatives Tetrahedron Lett. 552366

42. Kangani M, Hazeri N, Mghsoodlou M T, Habibikhorasani S M and Salahi S 2015 Green synthesis of
1, 4-dihydropyrano [2, 3-c] pyrazole derivatives using maltose as biodegradable catalyst Res. Chem. Inter. $\mathbf{4}$ 2513

43. Soltanzadeh Z, Imanzadeh G, Noroozi-Pesyan N and Şahin E 2017 Green synthesis of pyrazole systems under solvent-free conditions Green Chem. Lett. Rev. 3148

44. Khurana J M and Chaudhary A 2012 Efficient and Green Synthesis of $4 \mathrm{H}$-pyrans and $4 \mathrm{H}$-pyrano [2, 3-c] Pyrazoles Catalyzed by Task-specific Ionic Liquid [bmim] $\mathrm{OH}$ under Solvent-free Conditions Green Chem. Lett. Rev. 4633

45. Zolfigol M A, Afsharnadery F, Baghery S, Salehzadeh $S$ and Maleki F 2015 Catalytic applications of [HMIM] $\mathrm{C}$ (NO 2) 3: as a nano ionic liquid for the synthesis of pyrazole derivatives under green conditions and a mechanistic investigation with a new approach $R S C A d v .92$ 75555

46. Safaei S, Mohammadpoor-Baltork I, Khosropour A R, Moghadam M, Tangestaninejad $\mathrm{S}$ and Mirkhani V 2013 Copper (II) ionic liquid catalyzed cyclization-aromatization of hydrazones with dimethyl acetylenedicarboxylate: a green synthesis of fully substituted pyrazoles New J. Chem. 7 2037

47. Shelke S N, Mhaske G R, Bonifácio V D and Gawande M B 2012 Green synthesis and anti-infective activities of fluorinated pyrazoline derivatives Bioorg. Med. Chem. Lett. 225727

48. Maddila S, Rana S, Pagadala R, Kankala S, Maddila S and Jonnalagadda S B 2015 Synthesis of pyrazole-4-carbonitrile derivatives in aqueous media with $\mathrm{CuO} / \mathrm{ZrO}_{2}$ as recyclable catalyst Cat. Comm. 61 26

49. Heravi M M and Daraie M 2016 A novel and efficient five-component synthesis of pyrazole based pyrido [2, 3 -d] pyrimidine-diones in water: a triply green synthesis Molecules 4441

50. Siddiqui Z N and Farooq F 2012 Silica supported sodium hydrogen sulfate $\left(\mathrm{NaHSO}_{4}-\mathrm{SiO}_{2}\right)$ : A novel, green catalyst for synthesis of pyrazole and pyranyl pyridine derivatives under solvent-free condition via heterocyclic $\beta$-enaminones J. Mol. Cat. A: Chem. 363 451

51. Zonouz A M., Eskandari I and Khavasi H R 2012 A green and convenient approach for the synthesis of methyl 6-amino-5-cyano-4-aryl-2, 4-dihydropyrano [2, 3-c] pyrazole-3-carboxylates via a one-pot, multicomponent reaction in water Tetrahedron Lett. 415519

52. Al-Matar, H M, Khalil K D, Adam A Y and Elnagdi M H 2010 Green one pot solvent-free synthesis of pyrano [2, 3-c]-pyrazoles and pyrazolo [1, 5-a] pyrimidines Molecules 96619

53. Polshettiwar V and Varma R S 2010 Nanoorganocatalyst: magnetically retrievable ferrite-anchored glutathione for microwave-assisted Paal-Knorr reaction, aza-Michael addition, and pyrazole synthesis Tetrahedron 51091

54. Kumari K, Raghuvanshi D S, Jouikov V and Singh K N 2012 Sc (OTf) 3 -catalyzed, solvent-free domino synthesis of functionalized pyrazoles under controlled microwave irradiation Tetrahedron Lett. 91130 
55. Hasaninejad A and Firoozi S 2013 Catalyst-free, onepot, three-component synthesis of 5-amino-1, 3-aryl1 \$ \$ $\mathrm{H}$ \$-pyrazole-4-carbonitriles in green media Mol. Div. 3459

56. Saha A, Payra S and Banerjee S 2015 One-pot multicomponent synthesis of highly functionalized bioactive pyrano [2, 3-c] pyrazole and benzylpyrazolyl coumarin derivatives using $\mathrm{ZrO} 2$ nanoparticles as a reusable catalyst Green Chem. 52859

57. Khurana J M, Nand B and Kumar S 2011 Rapid synthesis of polyfunctionalized pyrano [2, 3-c] pyrazoles via multicomponent condensation in room-temperature ionic liquids Synth. Comm. 3405

58. Srivastava M, Rai P, Singh J and Singh J 2013 An environmentally friendlier approach-ionic liquid catalysed, water promoted and grinding induced synthesis of highly functionalised pyrazole derivatives $R S C A d v$. 3816994

59. Frizzo C P, Marzari M R, Buriol L, Moreira D N, Rosa F A, Vargas P S, Zanatta N, Bonacorso H G and Martins M A 2009 Ionic liquid effects on the reaction of $\beta$ enaminones and tert-butylhydrazine and applications for the synthesis of pyrazoles Cat. Comm. 151967

60. Hany F A and Mohamed H E 2009 Recent developments in aminopyrazole chemistry ARKIVOC 1198

61. Von R 1849 Pyrrole reaction R. Chem. Ber. 27685

62. Taylor E C and Hartke K S J 1959 The Reaction of Malononitrile with Substituted Hydrazines: New Routes to 4-Aminopyrazolo[3,4-d]pyrimidines Am. Chem. Soc. 812456

63. Eberts F S 1961 1, 1, 3-Tricyano-2-amino-1-propene (U-9189), a Biologically active component of aqueous solutions of malononitrile Arch. Biochem. Biophys. 95 305

64. Shruti K, Krunal P, Nilesh D, Palak S, Parita S and Shruti Kushwah 2012 Synthesis of pyrazole azo dyes Ijprbs 2287

65. Barry H M, Mark H, Bury and Roy M 2001 "Pyyrole synthesis" U.S. Patent 6200371 B1

66. Hamid M H, Nada M A and Huwaida M H 2010 Synthesis of pyrazole Nat. Sci. 21349

67. Sabir H, Deepika K and Mukta S 2010 Synthesis and Biological Evaluation of Some New 1-substituted-3,5dimethyl-4-[(Substituted Phenyl) Diazenyl] Pyrazole Derivatives Am.-Eur. J. Sci. Res. 4257

68. Ibrahim M K A, Ramiz M M M and El-Ghandour A H H 1989 Synthesis of n-(azolyl)-alpha-ketohydrazidoyl chlorides, azolotriazole and azolotriazine derivatives $J$. Chem. Soc. Pak. 11291

69. Swelam S A, El-Said N S, Aly A S and Abdel-Fatth A M 2009 Production of pyrans, pyridazines, pyrimidines, pyrazines and triazine compounds using benzoylacetonitriles as a precursor Inter. J. Pharm. Tech. Res. 1 445

70. Ahmed E, Fadda A A, Khalil A M, Ameen T A E and Farid A B 2009 Synthesis, antitumor evaluation, molecular modeling and quantitative structure-activity relationship (QSAR) of some novel arylazopyrazolodiazine and triazine analogs Bioorg. Med. Chem. 17 5096

71. Niţu S V, Bercean V N, Badea V and Csunderlik C 2008 Azoic Compounds Obtained from
1H-4-ethoxycarbonyl-3-methyl-5-aminopyrazole and 1, 3-disubstituted 1H-pyrazol-5-ones Chem. Bull. 53 1

72. Metwally M A, Gouda M A, Ammar N H and Khalil A M 2012 Inter. J. Mod. Org. Chem. 196

73. Fati K and Fikret K 2008 Synthesis of some novel pyrazolo $[5,1-c][1,2,4]$ triazine derivatives and investigation of their absorption spectra Dye Pig. 7697

74. Fati K and Fikret K 2008 Synthesis and absorption spectra of some novel heterocyclic disazo dyes derived from pyridone and pyrazolone derivatives Dye Pig. 76 147

75. Ahmed A F, Samir B, Ramy R and Hassan A 2008 Cyanoacetamide Derivatives as Synthons in Heterocyclic Synthesis Turk. J. Chem. 32259

76. Abu-Shanab F A, Mousa S A, Eshak E A, Sayed A Z and Al-Harrasi A 2011 Dimethylformamide dimethyl acetal (DMFDMA) in heterocyclic synthesis: Synthesis of polysubstituted pyridines, pyrimidines, pyridazine and their fused derivatives Int. J. Org. Chem. 1 207

77. Abdel-Zaher A E, H H D, Nouria A A and Elnagdia M H 2007 Chemistry of carbofunctionally substituted hydrazones ARKIVOC 2272

78. Abunada N M, Hassaneen, Kandile N G and Miqdad O A 2008 Synthesis and biological activity of some new pyrazoline and pyrrolo [3,4-c]pyrazole-4,6-dione derivatives: reaction of nitrilimines with some dipolarophiles Molecules 131011

79. Chawla R, Sahoo U, Arora A, Sharma P C and Radhakrishnan V 2010 Microwave assisted synthesis of some novel 2-pyrazoline derivatives as possible antimicrobial agents Acta Pol. Pharm. 67155

80. Jadhav S B, Shastri R A, Gaikwad K V and Gaikwad S V 2009 Synthesis and antimicrobial studies of some novel pyrazoline and isoxazoline derivatives Eur. J. Chem. 6 83

81. Kaur H, Kumar S, Singh I and Kumar A 2010 Synthesis, characterization and antibacterial activity of various substituted oxadiazolylpyrazolinyl/isoxazolinylcoumarin derivatives Int. J. Pharm. Sci. Res. 1 58

82. Faidallah H M, Rostom S A and Al-Saadi M S 2010 Synthesis and biological evaluation of some new substituted fused pyrazole ring systems as possible anticancer and antimicrobial agents JKAU Sci 22177

83. Dean A. Heathcote, Hetal P, Sebastian H B K, Pascale H, Manikandan P, Mary A, Seshu K K, Ashutosh S J,Bodo S, Marion B, Andreas B, Jan B and Alekasandra S 2010 A novel pyrazolo [1, 5-a] pyrimidine is a potent inhibitor of cyclin-dependent protein kinases 1,2, and 9, which demonstrates antitumor effects in human tumor xenografts following oral administration J. Med. Chem. 538508

84. Zask A, Verheijen J C, Curran K, Kaplan J, Richard D J, Nowak P, Malwitz D J, Brooijmans N, Bard J, Svenson K and Lucas J 2009 ATP-competitive inhibitors of the mammalian target of rapamycin: design and synthesis of highly potent and selective pyrazolopyrimidines $J$. Med. Chem. 525013

85. Guertin D A and Sabatini D M 2007 Defining the Role of mTOR in Cancer Cancer Cell 129 
86. Chiang G G and Abraham R T 2007 Targeting the mTOR signaling network in cancer Trends Mol. Med. 13433

87. Bhaskar V H and Mohitea P B 2011 Synthesis analgesic, anti-inflammatory and antimicrobial activities of some 1-[5-(substituted phenyl)-4,5-dihydro-1hpyrazol3-yl]-5-phenyl-1h-tetrazole J. Optoelectron. Biomed. Mat. 37

88. Venkataraman S, Jain S, Shah K and Upmanyu N 2010 Synthesis and biological activity of some novel pyrazolines Acta Pol. Pharm. 67361

89. Sridevi C, Balaji K and Naidu A 2011 Synthesis and pharmacological evaluation of some phenylpyrazolo indoquinoxaline derivatives E-J. Chem. 8924

90. Menozzi G, Merello L, Fossa P, Silvia S, Angelo R, Luisa M, Francesco B, Roberta L, Chiara M, Valeria M, Paolo L, C and Elena T 2009 Synthesis and evaluation of electron-rich curcumin analogues Bioorg. Med. Chem. Lett. 1360

91. Ayoob B, Maryam M K and Ali A S 2008 One-pot synthesis and antibacterial activities of pyrazolo[4',3':5,6]pyrido[2,3-d]pyrimidine-dione derivatives Bioorg. Med. Chem. Lett. 215800

92. Kumar R, Malik S and Chandra R 2009 Synthesis and antimicrobial activity of 4-[5-chloro-3-methyl1-phenyl-1H-pyrazol-4-yl]-dihydropyridines and 4-[5-chloro-3-methyl-1-phenyl-1H-pyrazol-4-yl]-3, 4-dihydropyrimidin-2-ones Indian J. Chem. B 49718

93. Sahu S K, Banerjee M, Samantray A, Behera C and Azam M A 2008 Synthesis and antiviral evaluation of some new pyrazole and pyrazolopyrimidine derivatives Trop J. Pharm. Res. 7961

94. Sivakumar K K, Rajasekaran A, Ponnilavarasan I, Somasundaram A and Kamalaveni S 2010 Synthesis and evaluation of anti-microbial analgesic activity of some (4Z) -3-methyl-1-[(2-oxo-2H-chromen-4-yl) carbonyl] -1H-pyrazole-4, 5-dione-4- [(substitutedphenyl) hydrazone] Der Pharm. Lett. 2211

95. Dias L R and Salvador R R S 2012 Pyrazole Carbohydrazide Derivatives of Pharmaceutical Interest Pharmaceuticals 5317

96. Prathap K J, Himaja M, Mali S V, Karigar A A and Sikarwar M S 2011 Synthesis of New 3-Aryl-1-(5(pyridin-3-yl)-1,3,4-thiadiazol-2-yl)-1H-pyrazole-4-ca rbaldehydes as Antitubercular Agents Drug Inv. 3 10

97. El-Sabbagh O I, Baraka M M, Ibrahim S M, Pannecouque P, Andrei G, Snoeck R, Balzarini J and Rashad A 2009 Synthesis and antiviral activity of new pyrazole and thiazole derivatives Eur. J. Med. Chem. 44 3746

98. Rashad A E, Hegab M I, Abdel-Megeid R E,Micky J A and Abdel-Megeid F M E 2008 Synthesis and antiviral evaluation of some new pyrazole and fused pyrazolopyrimidine derivatives Bioorg. Med. Chem. 16 7102

99. El-Badawi S M A and Bakhiet A O 2012 Chemotherapeutic and economic potentials of some lactiferous plants J. Med. Plant Res. 63278

100. Priyadarsini P, Ujwala, B, Venkata R C and Madhava R V 2012 Synthesis and antimicrobial activity of some novel pyrazoles Der Pharm. Lett. 41123
101. Hassan S Y 2013 Synthesis, Antibacterial and antifungal activity of some new pyrazoline and pyrazole derivatives Molecules 182683

102. Turan Z G, Chevallet P, Kilic T S and Erolic K 2000 Synthesis of some thiazolyl-pyrazoline derivatives and preliminary investigation of their hypotensive activityEur. J. Med. Chem. 35635

103. Silver K S and Soderlund D M 2005 Action of pyrazoline type insecticides at neuronal target side Pestic. Biochem. Physiol. 81136

104. Godey M C M, Fighera M R, Souza F R, Rubin M A, Oliveira M R, Zennata N and Mello C F 2004 a2-Adrenoceptors and 5-HT receptors mediate the antinociceptive effect of new pyrazolines, but not of dipyrone Eur. J. Pharma. 49693

105. Chimenti P, Granese A, Rivanera D, Lilli D, Scaltrito M M and Brenciaglia M I 2005 Synthesis and in vitro selective anti-Helicobacter pylori activity of pyrazoline derivatives Bioorg. Med. Chem. Lett. 15603

106. Salgin-Goksen U, Yabanoglu-Ciftci S, Ercan A, Yelekci K, Ucar G and Gokhan-Kelekci N 2013 Evaluation of selective human MAO inhibitory activities of some novel pyrazoline derivatives J. Neural. Transm. 120863

107. Bonesi M, Loizzo M R, Statti G A, Michel S, Tillequin F and Menichini 2010 The synthesis and angiotensin converting enzyme (ACE) inhibitory activity of chalcones and their pyrazole derivatives Bioorg. Med. Chem. Lett. 201990

108. Gao M, Wang M, Miller K D and Zheng Q H 2001 Synthesis and preliminary in vitro biological evaluation of new carbon-11-labeled celecoxib derivatives as candidate PET tracers for imaging of COX-2 expression in cancer Eur. J. Med. Chem. 464760

109. Mumolo M, Zumieri D, Fulgani V, Vio L and Bunfi E 2001 Synthesis and antimycobacterial activity of 5-aryl-1-isonicotinyl-3-(pyridyl-2-yl)-4,5-dihydro1Hpyrazole derivatives Frmaco 56593

110. Ozdamir A and Zitouni G T 2008 Novel analogues of 2- pyrazoline: Synthesis, characterization and antimycobacterial evaluation Turk. J. Chem. 32529

111. Zampieri D, Mamolo M G, Lourini E, Sciolino G, Bunfi E and Vio L 2008 Antifungal and antimycobacterial activity of 1-(3, 5-diaryl-4, 5-dihydro-1H-pyrazol-4yl)-1H-imidazole derivatives Bioorg. Med. Chem. 16 4516

112. Sreenivasa G M, Jaychandran E, Shivkumar B, Kumar K J and Vijay K V 2009 Synthesis of bioactive molecule fluoro benzothiazole comprising potent heterocyclic moieties for anthelmintic activity Arch. Pharm. Sci. Res. 1150

113. Faisal M, Larik F A and Saeed A 2018 A highly promising approach for the one-pot synthesis of biscoumarins using HY zeolite as recyclable and green catalyst $J$. Porous Mater. 26455

114. Charles E M, Catherine B, Romuald C, Simon G, Michael H, Manos P, Isabelle T, David A P, Faye J Q, Matthew D S, Paul A S and Rob W 2009 Pyrazole NNRTIs 4: selection of UK-453,061 (lersivirine) as a development candidate Bioorg. Med. Chem. Lett. 19 5857

115. Kasralikar H M, Jadhavar S C, Goswami S V, Kaminwar N S and Bhusare S R 2019 Design, Synthesis 
and Molecular Docking of Pyrazolo [3, 4d] thiazole hybrids as Potential Anti-HIV-1 NNRT Inhibitors Bioorg. Chem. 86437

116. Vekariya M K, Vekariya R H, Patel K D, Raval N P, Shah P U, Rajani D P and Shah N K 2018 PyrimidinePyrazole Hybrids as Morpholinopyrimidine-Based Pyrazole Carboxamides: Synthesis, Characterisation, Docking, ADMET Study and Biological Evaluation Chem. Select. 36998

117. Nassar E 2010 Synthesis, (in vitro) Antitumor and Antimicrobial Activity of some Pyrazoline, Pyridine, and Pyrimidine Derivatives Linked to Indole Moiety $J$. Am. Sci. 68

118. Feng J, Qi H, Sun X, Feng S, Liu Z, Song Y and Qiao X 2018 Synthesis of novel pyrazole derivatives as promising DNA-binding agents and evaluation of antitumor and antitopoisomerase I/II activities Chem. Pharm. Bull. c18 546

119. Pasin J S M, Ferreria A P O, Saraiva A L L, Ratzlaff V, Andrighetto R, Machado P, Marchesam S, Zanette R A and Martins M A P 2010 Antipyretic and antioxidant activities of 5- trifluoromethyl-4,5dihydro-1H-pyrazoles in rats Braz. J. Med. Biol. Res. 43 1193

120. Chimenti F, Bolasco A, Manna F, Secci D, Chimenti P, Befani O, Turini P, Giovannini V, Mondovì B, Cirilli R and Torre F L 2004 Synthesis and selective inhibitory activity of 1-acetyl-3, 5-diphenyl-4, 5-dihydro-(1 H)pyrazole derivatives against monoamine oxidase $J$. Med. Chem. 472071
121. Abdel-Aziz M, Abuo-Rahman G E A and Hassan A A 2009 Synthesis of novel pyrazole derivatives and evaluation of their antidepressant and anticonvulsant activities Eur. J. Med. Chem. 443480

122. Wu Y, Huang Y P, Zhou S C, Tan Y Q, Xu B G, Liang Z and Deng X Q 2018 Synthesis of 1, 3-Diaryl Pyrazole Derivatives and Evaluation of Anticonvulsant and Antimicrobial Activities Lat. Am. J. Pharm. 37 1017

123. Dileep Kumar A, Bharath S, Dharmappa R N, Naveen S, Lokanath N K and Ajay Kumar K 2018 Design, synthesis and spectroscopic and crystallographic characterisation of novel functionalized pyrazole derivatives: biological evaluation for their cytotoxic, angiogenic and antioxidant activities Res. Chem. Intermediat. 445635

124. Cheng L, Shen Z H, Xu T M, Tan C X, Weng J Q, Han L, Peng W L and Liu X H 2018 Synthesis and Nematocidal Activity of N-Substituted 3-Methyl-1H-pyrazole-4carboxamide Derivatives Against Meloidogyne incognita J. Heterocycl. Chem. 55946

125. Fei C, Chen Y, Jiang Z and Jiang D 2018 Thioetherbridged arylalkyl-linked N-phenylpyrazole derivatives: Design, synthesis, insecticidal activities, structureactivity relationship and molecular-modeling studies Bioorg. Med. Chem. Lett. 281792

126. Dai H, Huang M, Qian J, Liu J, Meng C, Li Y, Ming G, Zhang T, Wang S, Shi Y and Yao Y 2019 Excellent antitumor and antimetastatic activities based on novel coumarin/pyrazole oxime hybrids Eur. J. Med. Chem. 166470 